\title{
Ammonia Emissions in the United States, European Union, and China Derived by High-Resolution Inversion of Ammonium Wet Deposition Data: Interpretation with a New Agricultural Emissions Inventory (MASAGE_NH3)
}

\section{Citation}

Paulot, F., Daniel James Jacob, R. W. Pinder, J. O. Bash, Katherine Rose Travis, and D. K. Henze. 2014. "Ammonia Emissions in the United States, European Union, and China Derived by HighResolution Inversion of Ammonium Wet Deposition Data: Interpretation with a New Agricultural Emissions Inventory (MASAGE_NH3)." Journal of Geophysical Research: Atmospheres 119 (7) (April 9): 4343-4364. doi:10.1002/2013jd021130. http://dx.doi.org/10.1002/2013JD021130.

\section{Published Version}

doi:10.1002/2013JD021130

\section{Permanent link}

http://nrs.harvard.edu/urn-3:HUL.InstRepos:13792759

\section{Terms of Use}

This article was downloaded from Harvard University's DASH repository, and is made available under the terms and conditions applicable to Other Posted Material, as set forth at http:// nrs.harvard.edu/urn-3:HUL.InstRepos:dash.current.terms-of-use\#LAA

\section{Share Your Story}

The Harvard community has made this article openly available.

Please share how this access benefits you. Submit a story. 
Journal of Geophysical Research: Atmospheres

\section{RESEARCH ARTICLE}

10.1002/2013JD021130

Key Points:

- Adjoint-based inversion of ammonium wet deposition in the U.S.,

Europe, and China

- Much larger spatial and temporal variability of U.S. emission than in the a priori

- New model of NH3 emissions reproduces the patterns of the optimized emissions

Correspondence to:

F. Paulot,

paulot@seas.harvard.edu

Citation:

Paulot, F., D. J. Jacob, R. W. Pinder, J. O. Bash, K. Travis, and D. K. Henze (2014), Ammonia emissions in the United States, European Union, and China derived by high-resolution inversion of ammonium wet deposition data: Interpretation with a new agricultural emissions inventory (MASAGE_NH3), J. Geophys. Res. Atmos., 119, 4343-4364, doi:10.1002/2013JD021130.

Received 4 NOV 2013

Accepted 14 MAR 2014

Accepted article online 19 MAR 2014

Published online 9 APR 2014

\section{Ammonia emissions in the United States, European Union, and China derived by high-resolution inversion of ammonium wet deposition data: Interpretation with a new agricultural emissions inventory (MASAGE_NH3)}

\author{
F. Paulot ${ }^{1}$, D. J. Jacob' ${ }^{1}$, R. W. Pinder ${ }^{2}$, J. O. Bash ${ }^{2}$, K. Travis ${ }^{1}$, and D. K. Henze ${ }^{3}$ \\ ${ }^{1}$ School of Engineering and Applied Sciences, Harvard University, Cambridge, Massachusetts, USA, ${ }^{2}$ U.S. EPA Office of \\ Research and Development, Research Triangle Park, North Carolina, USA, ${ }^{3}$ Department of Mechanical Engineering, \\ University of Colorado Boulder, Boulder, Colorado, USA
}

\begin{abstract}
We use the adjoint of a global 3-D chemical transport model (GEOS-Chem) to optimize ammonia $\left(\mathrm{NH}_{3}\right)$ emissions in the U.S., European Union, and China by inversion of 2005-2008 network data for $\mathrm{NH}_{4}^{+}$wet deposition fluxes. Optimized emissions are derived on a $2^{\circ} \times 2.5^{\circ}$ grid for individual months and years. Error characterization in the optimization includes model errors in precipitation. Annual optimized emissions are 2.8 $\mathrm{Tg} \mathrm{NH}_{3}-\mathrm{N} \mathrm{a}^{-1}$ for the contiguous U.S., $3.1 \mathrm{Tg} \mathrm{NH}_{3}-\mathrm{N} \mathrm{a}^{-1}$ for the European Union, and 8.4 $\mathrm{Tg} \mathrm{NH}_{3}-\mathrm{N} \mathrm{a}^{-1}$ for China. Comparisons to previous inventories for the U.S. and European Union show consistency $(\sim \pm 15 \%)$ in annual totals but some large spatial and seasonal differences. We develop a new global bottom-up inventory of $\mathrm{NH}_{3}$ emissions (Magnitude And Seasonality of Agricultural Emissions model for NH3 (MASAGE_NH3)) to interpret the results of the adjoint optimization. MASAGE_NH3 provides information on the magnitude and seasonality of $\mathrm{NH}_{3}$ emissions from individual crop and livestock sources on a $0.5^{\circ} \times 0.5^{\circ}$ grid. We find that U.S. emissions peak in the spring in the Midwest due to corn fertilization and in the summer elsewhere due to manure. The seasonality of European emissions is more homogeneous with a well-defined maximum in spring associated with manure and mineral fertilizer application. There is some evidence for the effect of European regulations of $\mathrm{NH}_{3}$ emissions, notably a large fall decrease in northern Europe. Emissions in China peak in summer because of the summertime application of fertilizer for double cropping.
\end{abstract}

\section{Introduction}

Industrial production of ammonia $\left(\mathrm{NH}_{3}\right)$ by the Haber-Bosch process has played a major role in the threefold global increase of food production from 1950 to 2000 [Mosier et al., 2004]. $\mathrm{NH}_{3}$-based fertilizers enable higher crop yields as $\mathrm{N}$ is a limiting nutrient. However, inefficiencies in the agricultural system result in large losses of $\mathrm{N}$ to the environment [Erisman et al., 2008] including NH3 emissions to the atmosphere [Houlton et al., 2012]. Agricultural activities are by far the largest global source of $\mathrm{NH}_{3}$ to the atmosphere [Bouwman et al., 1997].

Atmospheric $\mathrm{NH}_{3}$ has undesirable consequences. It contributes to aerosol formation with implications for air quality [Pope III et al., 2002, 2009; Aneja et al., 2009] and climate change [Adams et al., 2001; Martin et al., 2004]. Its transport and eventual deposition to nonagricultural ecosystems can affect carbon fixation [Pinder et al., 2012], eutrophication [Stevens et al., 2004; Grizzetti, 2011], and biodiversity [Sala et al., 2000; Bobbink et al., 2010; Dise, 2011]. Brink and van Grinsven [2011] estimate an annual cost of 18-140 billion US\$ for $\mathrm{NH}_{3}$ emissions in the European Union, mostly from increased mortality associated with aerosols. Without large changes in the present food system, the projected global increase in food demand $(70 \%$ by 2050 , Conforti [2011]) will be accompanied by greater $\mathrm{NH}_{3}$ emissions [Erisman et al., 2008].

Global agricultural emissions of $\mathrm{NH}_{3}$ have proven challenging to estimate with the spatial and temporal resolution required for atmospheric models. Detailed models of the nitrogen flow in agricultural systems have been developed for livestock operations [Pinder et al., 2004a, 2004b; Li et al., 2012] and mineral fertilizer [Cooter et al., 2012]. These models require a detailed knowledge of local environmental conditions and farming practices that is generally not available. Global "bottom-up" $\mathrm{NH}_{3}$ emission inventories rely on source specific emission factors, which account for regional practices [Klimont and Brink, 2004; Faulkner and Shaw, 
2008]. Recent evaluations of the U.S. National Emission Inventory (NEI) compiled by the U.S. Environmental Protection Agency (EPA, http://www.epa.gov/ttn/chief/net/2005inventory.html) show good agreement with observations on the national scale [Zhang et al., 2012] but large discrepancies on regional scale [Fisher et al., 2011; Walker et al., 2012; Nowak et al., 2012; Heald et al., 2012]. Uncertainties in $\mathrm{NH}_{3}$ emissions contribute to large errors in simulated ammonium nitrate [Pye et al., 2009; Heald et al., 2012], which makes up an important fraction of the aerosol [Zhang et al., 2007].

An alternate approach to constrain emissions is by inverse modeling of atmospheric observations. In this "top-down" approach, a chemical transport model (CTM) is used to relate emissions to the atmospheric variables being observed. CTM emissions assembled in a vector $\mathbf{E}$ are optimized by minimizing a $\chi^{2} \operatorname{cost}$ function $\mathcal{J}$ with contributions from the mismatch between observations and the model and from the mismatch between bottom-up ("a priori") and optimized emissions. The optimal emissions are obtained by solving the cost function minimization problem $\nabla_{\mathbf{E}} \mathcal{J}=0$. This can be done analytically by constructing the Jacobian of the CTM. Gilliland et al. $[2003,2006]$ used this approach to constrain the magnitude and seasonality of U.S. national $\mathrm{NH}_{3}$ emissions with the Community Multiscale Air Quality CTM and the dense network of $\mathrm{NH}_{4}^{+}$wet deposition data in the United States. The cost of the analytical approach increases rapidly as the dimension of $\mathbf{E}$ increases, and this effectively limits the resolution of the optimization. The limitation can be circumvented by using an adjoint methods that solves $\nabla_{\mathbf{E}} \mathcal{J}=0$ iteratively [Henze et al., 2007]. Adjoint methods allow to take full advantage of large ensembles of atmospheric data, as the resolution of the optimized emissions is limited solely by the information content of the data and by the horizontal resolution of the CTM. Zhu et al. [2013] used the adjoint of the GEOS-Chem CTM [Henze et al., 2007] to constrain $\mathrm{NH}_{3}$ emissions in the contiguous U.S. by inversion of $\mathrm{NH}_{3}$ observations from the Tropospheric Emission Spectrometer (TES) on board the Aura satellite [Shephard et al., 2011].

Here we use the adjoint of the global GEOS-Chem CTM to optimize $\mathrm{NH}_{3}$ emissions in the U.S., European Union, and China by inversion of $2005-2008 \mathrm{NH}_{4}^{+}$wet deposition flux data from regional acid deposition monitoring networks. The $\mathrm{NH}_{4}^{+}$wet deposition flux is an attractive constraint for $\mathrm{NH}_{3}$ emissions because both gaseous $\mathrm{NH}_{3}$ and aerosol $\mathrm{NH}_{4}^{+}$are efficiently scavenged by precipitation. CTM precipitation fields are a source of errors [Pinder et al., 2006] and we introduce here an approach to correct for it.

Inverse modeling can constrain the spatial and temporal distribution of emissions but offers no direct information on the underlying processes. In order to interpret the results and advance our understanding of $\mathrm{NH}_{3}$ emissions, we also develop as part of this work a new global bottom-up emission inventory called the Magnitude And Seasonality of Agricultural Emissions for $\mathrm{NH}_{3}$ (MASAGE_NH3) model. MASAGE_NH3 provides gridded $\left(0.5^{\circ} \times 0.5^{\circ}\right)$ seasonally resolved emission estimates informed by worldwide data on regional agricultural activities.

\section{Bottom-Up Emission Inventories}

\subsection{A Priori Emission Inventories}

Table 1 summarizes the global emissions of $\mathrm{NH}_{3}$ used as a priori values for the inversion. Annual anthropogenic emissions are from the Global Emissions Inventory Activity (GEIA) [Bouwman et al., 1997], superseded by regional inventories for the U.S. (EPA NEI05 for 2005, http://www.epa.gov/ttnchie1/net/ 2005inventory.html), Europe (European Monitoring and Evaluation Programme (EMEP) [Tørseth et al., 2012]), East Asia [Streets et al., 2003], and Canada (Climate Analysis Center, http://www.ec.gc.ca/pdb/cac/cachomee. $\mathrm{cfm})$. Over $80 \%$ of total emissions in each region is from anthropogenic sources (almost entirely agriculture). Natural sources of $\mathrm{NH}_{3}$ include soil, vegetation, wild animals, and the ocean and are taken from the GEIA inventory [Bouwman et al., 1997]. Fire emissions are calculated using the Global Fire Emissions Database version 2 (GFED2) with monthly resolution [Randerson et al., 2006]. Our a priori anthropogenic emissions in Europe, Asia, and the U.S. have annual resolution. Anthropogenic $\mathrm{NH}_{3}$ emissions are distributed monthly following Friedrich and Reis [2004] for Europe, Fisher et al. [2011] for Asia, and Park et al. [2004] in the United States. These seasonalities are derived independently of the annual bottom-up estimates, which can lead to inconsistencies. For instance, in the U.S., the NEI05 $\mathrm{NH}_{3}$ emissions for August are extrapolated to other months using an exponential temperature dependence [Aneja et al., 2000; Park et al., 2004]. Unlike in recent versions of the U.S. NEI (ftp://ftp.epa.gov/EmisInventory/2011v6/v1 platform), there is no diurnal or daily variation in $\mathrm{NH}_{3}$ emissions. This results in differences between the seasonality and the magnitude of $\mathrm{NH}_{3}$ emissions in the original NEI05 and in GEOS-Chem. In particular, U.S. annual anthropogenic $\mathrm{NH}_{3}$ emissions 
Table 1. Estimated $\mathrm{NH}_{3}$ Emissions ${ }^{\mathrm{a}}$

\begin{tabular}{lcccc} 
& Contiguous U.S. & European Union & China & World $^{\mathrm{b}}$ \\
\hline This work & & & & \\
A prioric $^{\mathrm{C}}$ & 2.6 & 3.7 & 11.1 & 58 \\
Optimized $^{\mathrm{d}}$ & 2.8 & 3.1 & 8.4 & 54 \\
MASAGE_NH3 $^{\mathrm{e}}$ & 2.7 & 3.0 & 8.4 & 54 \\
EDGAR v4.2 $^{\mathrm{f}}$ & 2.9 & 4.2 & 8.8 & 35 \\
National inventories $^{\text {Other estimates }}$ & $3.1^{\mathrm{g}}$ & $3.1^{\mathrm{h}}$ & & \\
\hline
\end{tabular}

${ }^{a} \mathrm{Tg} \mathrm{NH}_{3}-\mathrm{N} \mathrm{a}^{-1}$, where $\mathrm{NH}_{3}-\mathrm{N}$ refers to nitrogen in the form of ammonia. Values are for years 2005-2008, except for other estimates.

boptimization of global emissions is driven solely by observations over Canada, the U.S., the European Union, and East Asia.

'See section 2.1.

${ }^{d}$ From the adjoint inversion of $\mathrm{NH}_{4}^{+}$wet deposition flux data.

eNew global bottom-up inventory (see section 2.2 and Appendix).

fGlobal bottom-up inventory [European Commission, 2011] does not include natural emissions, which are estimated to account for $20 \%$ of global emissions [Bouwman et al., 1997].

9National Emission Inventory from the U.S. Environmental Protection Agency does not include natural emissions.

${ }^{h}$ EMEP does not include natural emissions.

i Pinder et al. [2006], Gilliland et al. [2006], and Zhang et al. [2012].

j'streets et al. [2003] and Huang et al. [2012].

${ }^{\mathrm{k}}$ Schlesinger and Hartley [1992], Bouwman et al. [1997], Holland et al. [1999], and Galloway et al. [2004].

in the U.S. are 35\% (2.0 $\mathrm{Tg} \mathrm{NH}_{3}-\mathrm{N} \mathrm{a}^{-1}$ ) lower in GEOS-Chem than in the original NEI05. Here and elsewhere $\mathrm{Tg} \mathrm{NH}_{3}-\mathrm{N} \mathrm{a}^{-1}$ refers to $\mathrm{TgN}$ as $\mathrm{NH}_{3}$.

\subsection{New Bottom-Up Inventory of Agricultural Emissions (MASAGE_NH3 Model)}

The different $\mathrm{NH}_{3}$ emission inventories currently implemented in GEOS-Chem do not distinguish between the different anthropogenic sources of $\mathrm{NH}_{3}$. These information are important to interpret the changes in the spatial and temporal distribution suggested by our top-down emission estimates (see section 3). This motivated us to develop a new global bottom-up inventory of $\mathrm{NH}_{3}$ emissions. We focus on agricultural emissions, which dominate on a global scale, and adopt nonagricultural emissions from previous work by Lamarque et al. [2010] for other anthropogenic emissions, Randerson et al. [2006] for open fires, and Bouwman et al. [1997] for natural emissions. Natural emissions are reduced by $50 \%$ over the U.S. $\left(0.27 \mathrm{Tg} \mathrm{NH}_{3}-\mathrm{N} \mathrm{a}^{-1}\right)$ and European Union (0.2 $\mathrm{Tg} \mathrm{NH}_{3}-\mathrm{N} \mathrm{a}^{-1}$ (EU27)) based on evidence that the Bouwman et al. [1997] inventory is too high for these sources [Battye and Barrows, 2004; Simpson et al., 1999].

Our Magnitude And Seasonality of Agricultural Emissions model for $\mathrm{NH}_{3}$ (MASAGE_NH3) is produced on a $0.5^{\circ} \times 0.5^{\circ}$ horizontal grid. Details on the methodology are in the Appendix. The magnitude of annual $\mathrm{NH}_{3}$ emissions from mineral fertilizer is calculated by combining the Monthly Irrigated and Rainfed Crop Areas (MIRCA) inventory of crop acreages $\left(0.5^{\circ} \times 0.5^{\circ}\right.$, Portmann et al. [2010]), crop- and country-specific fertilizer application rates [Heffer, 2009; FAOSTAT, 2009] and fertilizer-, crop-, and application-specific emission factors [Bouwman et al., 2002b]. Emissions are assumed to take place in the same month as fertilizer application [Plöchl, 2001]. Three application periods are considered: at planting, after harvest, and at the peak of the crop nutrient demand. Depending on the crop, these different stages are either calculated following the approach of Bondeau et al. [2007] or taken from a global survey [Sacks et al., 2010]. The magnitude of annual $\mathrm{NH}_{3}$ emissions from manure management is calculated by combining the global distribution of livestock $\left(0.5^{\circ} \times 0.5^{\circ}\right.$, Wint and Robinson [2007]) with region- and livestock-specific annual emission factors [Bouwman et al., 1997; Faulkner and Shaw, 2008; Velthof et al., 2012]. Emissions are divided between housing, storage, and manure application. We follow Gyldenkærne et al. [2005] to represent the effect of temperature and wind speed on $\mathrm{NH}_{3}$ emissions from manure and mineral fertilizer application. The MASAGE_NH3 model is driven here by the GEOS-5 meteorology with a spatial resolution of $2^{\circ} \times 2.5^{\circ}$ and a temporal resolution of $3 \mathrm{~h}$.

Table 2 compares the annual emissions predicted by the MASAGE_NH3 model with previous bottom-up inventories, and Table A1 provides further detail on MASAGE_NH3 emissions. At the continental scale, we 
Table 2. MASAGE_NH3 Inventory of Agricultural $\mathrm{NH}_{3}$ Emissions ${ }^{\mathrm{a}}$

\begin{tabular}{|c|c|c|c|}
\hline & Mineral Fertilizer & Manure & Total Agriculture \\
\hline World & $\begin{array}{c}9.4 \\
\left(10-12^{b}, 24^{c}\right)\end{array}$ & $\begin{array}{c}24 \\
\left(16-27^{b}, 8.6^{c}\right)\end{array}$ & $\begin{array}{c}34 \\
\left(27-38^{b}, 33^{c}\right)\end{array}$ \\
\hline Contiguous U.S. & $\begin{array}{c}0.5 \\
\left(1.6^{c}, 0.7^{d}\right)\end{array}$ & $\begin{array}{c}1.7 \\
\left(2.1^{\mathrm{b}}, 1.0^{\mathrm{c}}, 1.7^{\mathrm{e}}\right)\end{array}$ & $\begin{array}{c}2.2 \\
\left(2.6^{\mathrm{c}}, 2.7^{\mathrm{e}}\right)\end{array}$ \\
\hline European Union & $\begin{array}{c}0.6 \\
\left(2.2^{c}, 0.5^{f}\right)\end{array}$ & $\begin{array}{c}2.0 \\
\left(1.9^{\mathrm{c}}, 2.4^{\mathrm{f}}\right)\end{array}$ & $\begin{array}{c}2.6 \\
\left(4.1^{c}, 2.9^{9}\right)\end{array}$ \\
\hline China & $\begin{array}{c}3.0 \\
\left(6.8^{\mathrm{c}}, 2.6^{\mathrm{h}}, 5.5^{\mathrm{i}}\right)\end{array}$ & $\begin{array}{c}4.8 \\
\left(1.9^{\mathrm{c}}, 4.4^{\mathrm{h}}, 4.1^{\mathrm{i}}\right)\end{array}$ & $\begin{array}{c}7.8 \\
\left(8.7^{c}, 7^{h}, 9.6^{i}\right)\end{array}$ \\
\hline
\end{tabular}

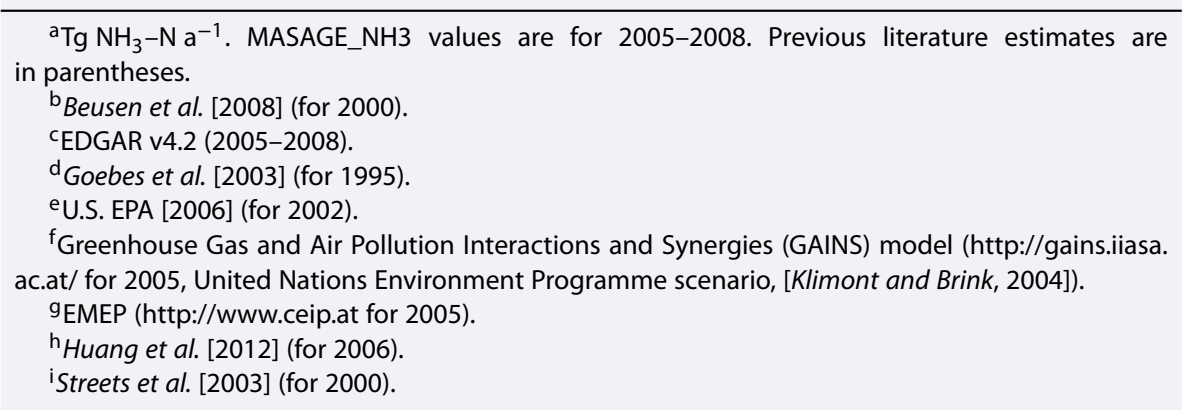

find manure emissions to be larger than fertilizer emissions. This differs from Emission Database for Global Atmospheric Research (EDGAR v4.2.) European emissions are consistent with the detailed EMEP inventory and $40 \%$ lower than EDGAR v4.2. Fertilizer accounts for a larger fraction of agricultural emissions in China than in the U.S. and European Union. This reflects elevated fertilizer application rates, the extensive use of ammonium bicarbonate that has large $\mathrm{NH}_{3}$ loss [Huang et al., 2012], and lower cattle and dairy production relative to pork and poultry. Emission per inhabitant is similar in China $\left(6.3 \mathrm{~kg} \mathrm{NH}_{3}-\mathrm{N} \mathrm{a}^{-1}\right.$ capita $\left.{ }^{-1}\right)$, European Union (7.3 $\mathrm{kg} \mathrm{NH}_{3}-\mathrm{Na}^{-1}$ capita $\left.{ }^{-1}\right)$, and the U.S. $\left(8.4 \mathrm{~kg} \mathrm{NH}_{3}-\mathrm{N} \mathrm{a}^{-1}\right.$ capita $^{-1}$ ).

\section{Top-Down Emission Estimates}

\subsection{Observations}

We use monthly observed wet deposition fluxes of $\mathrm{NH}_{4}^{+}$for $2005-2008$ from the U.S. National Atmospheric Deposition Program (NADP, 250 sites), the Canadian Air and Precipitation Monitoring Network (CAPMoN, $\sim 25$ sites, 2005-2007), the nonurban sites from the Acid Deposition Monitoring Network in East Asia (EANET, $\sim 30$ sites) and the European Monitoring and Evaluation Programme (EMEP, 70 sites). We use monthly wet deposition to limit the influence of model error in the timing of precipitation. These sites measure both precipitation and $\mathrm{NH}_{4}^{+}$concentrations, from which $\mathrm{NH}_{4}^{+}$wet deposition fluxes can be calculated.

We map the data onto the $2^{\circ} \times 2.5^{\circ}$ horizontal grid of GEOS-Chem in order to compare model and observations. Variability in precipitation over the $2^{\circ} \times 2.5^{\circ}$ grid can cause error in this mapping. Here we follow the methodology described by Latysh and Wetherbee [2012] and used by NADP. Observed $\mathrm{NH}_{4}^{+}$concentrations are first interpolated onto the grid of a high-resolution precipitation data set using inverse distance weighting. The resulting wet deposition fluxes are then averaged on the $2^{\circ} \times 2.5^{\circ}$ grid. We use high-resolution precipitation observations from PRISM (Parameter-elevation Regression on Independent Slopes Model) over the U.S. [Di Luzio et al., 2008], E-OBS over Europe [Haylock et al., 2008], and APHRODITE (Asian Precipitation Highly-Resolved Observational Data Integration Towards Evaluation of water resources) over East Asia in 2005-2007 [Yatagai et al., 2012]. We directly average the wet deposition flux data from CAPMoN and from EANET (2008) as we are not aware of independent high-resolution precipitation data sets. Because of the sparse coverage of the CAPMoN network, we use it solely as a supplement to the NADP data for constraining U.S. emissions.

\subsection{GEOS-Chem CTM}

We use the GEOS-Chem global 3-D chemical transport model v8.2.1 (www.geos-chem.org, Park et al. [2004]) to relate $\mathrm{NH}_{3}$ emissions to $\mathrm{NH}_{4}^{+}$wet deposition fluxes. The model is driven by assimilated meteorological data from the NASA Goddard Earth Observing System (GEOS-5) with horizontal resolution of $0.5^{\circ} \times 0.67^{\circ}$ 
and 72 vertical levels. The three lowest levels are centered at 58, 18, and $320 \mathrm{~m}$ above the surface. We degrade the horizontal resolution to $2^{\circ} \times 2.5^{\circ}$ for use in GEOS-Chem.

Gas-aerosol fractionation of $\mathrm{NH}_{x} \equiv \mathrm{NH}_{3}$ (gas) $+\mathrm{NH}_{4}^{+}$(aerosol) originating from $\mathrm{NH}_{3}$ emissions depends on the local atmospheric concentrations of sulfuric acid $\left(\mathrm{H}_{2} \mathrm{SO}_{4}\right)$ and total inorganic nitrate $\left(\mathrm{NO}_{3 T} \equiv \mathrm{HNO}_{3}+\right.$ $\mathrm{NO}_{3}^{-}$(aerosol)) originating from $\mathrm{SO}_{2}$ and $\mathrm{NO}_{x}$ emissions. In the presence of $\mathrm{H}_{2} \mathrm{SO}_{4}, \mathrm{NH}_{3}$ can partition to the aerosol phase by forming ammonium bisulfate $\left(\mathrm{NH}_{4} \mathrm{HSO}_{4}\right)$ and ammonium sulfate $\left(\left(\mathrm{NH}_{4}\right)_{2} \mathrm{SO}_{4}\right)$. If excess $\mathrm{NH}_{3}$ remains, it can further neutralize $\mathrm{HNO}_{3}$ and form ammonium nitrate aerosol $\left(\mathrm{NH}_{4} \mathrm{NO}_{3}\right)$. The thermodynamic equilibrium that controls $\mathrm{NH}_{x}$ gas-aerosol partitioning is simulated with the Regional Particulate Model Aerosol Reacting System (RPMARES) model [Binkowski and Roselle, 2003]. Atmospheric oxidation of $\mathrm{NH}_{3}$ is slow [Sander et al., 2011] and is not considered, such that $\mathrm{NH}_{x}$ is entirely removed by wet and dry deposition.

Wet deposition in GEOS-Chem is as described by Liu et al. [2001] and Wang et al. [2011] for aerosols and by Amos et al. [2012] for gases. The scheme accounts for scavenging in convective updrafts as well as in-cloud and below-cloud scavenging from large-scale precipitation. Gaseous $\mathrm{NH}_{3}$ is scavenged by warm clouds and rain on the basis of its solubility in water. It has a retention coefficient of $5 \%$ for riming in mixed clouds, and is not scavenged by cold (ice) clouds. Aerosol $\mathrm{NH}_{4}^{+}$is fully incorporated in cloud droplets and ice crystals. Extensive comparisons to observations in the GEOS-Chem literature indicate that the model provides an overall unbiased representation of scavenging, as shown, for example, by combined simulation of sulfate aerosol concentrations and wet deposition fluxes [Zhang et al., 2012], or simulation of ${ }^{210} \mathrm{~Pb}$ and ${ }^{7} \mathrm{Be}$ aerosol lifetimes [Amos et al., 2012; Barrett et al., 2012].

Dry deposition is calculated using a standard resistance-in-series model [Wesely, 1989; Wang et al., 1998] applied to a surface-type data base from Olson [1992]. The annual mean daytime dry deposition velocities of $\mathrm{NH}_{3}$ and $\mathrm{NH}_{4}^{+}$in the contiguous U.S. are $0.65 \mathrm{~cm} \mathrm{~s}^{-1}$ and $0.15 \mathrm{~cm} \mathrm{~s}^{-1}$, respectively [Zhang et al., 2012]. Simulated total wet and dry deposition fluxes of $\mathrm{NH}_{x}$ in the contiguous U.S. are 1.3 and $1.0 \mathrm{Tg} \mathrm{NH}_{3}-\mathrm{N} \mathrm{a}^{-1}$, respectively [Zhang et al., 2012].

Simulation of $\mathrm{NH}_{x}$ in GEOS-Chem is generally conducted as part of a standard detailed simulation of oxidant-aerosol chemistry to obtain the $\mathrm{H}_{2} \mathrm{SO}_{4}$ and $\mathrm{NO}_{3 \mathrm{~T}}$ fields needed to compute $\mathrm{NH}_{x}$ gas-aerosol partitioning [Park et al., 2004; Zhang et al., 2012]. This would incur considerable computational expense in our case, as the adjoint optimization is iterative. Here we use archived 3-D concentration fields of $\mathrm{SO}_{4}^{2-}$ and $\mathrm{NO}_{3 \mathrm{~T}}$ with half-hour resolution from a standard simulation similar to Zhang et al. [2012]. In this manner we can reproduce the $\mathrm{NH}_{x}$ fields from the standard simulation in a simulation using $\mathrm{NH}_{3}$ and $\mathrm{NH}_{4}^{+}$as the only transported species, and we can rapidly diagnose the sensitivity of $\mathrm{NH}_{x}$ wet deposition fluxes to change in $\mathrm{NH}_{3}$ emissions. Some error is induced by not resolving the effect of changing $\mathrm{NH}_{3}$ emissions on the lifetime of $\mathrm{NO}_{3 \mathrm{~T}}$. For a global reduction of $\mathrm{NH}_{3}$ emissions by $30 \%$, we find that $\mathrm{NO}_{3}$ decreases by less than $5 \%$ over Europe and the United States. Zhang et al. [2012] evaluated simulated $\mathrm{SO}_{4}^{2-}$ and $\mathrm{NO}_{3 \mathrm{~T}}$ over the U.S. and found good agreement with observations. Similarly, comparison of GEOS-Chem spring $\mathrm{SO}_{4}^{2-}$ wet deposition fluxes to observations in Europe and Asia indicate no consistent biases [Fisher et al., 2011]. The lower computational expense afforded by our simplification enables us to carry the adjoint optimization over a 4 year time period (2005-2008) and improves the robustness of the optimized emissions.

\subsection{Adjoint Model-Based Inversion}

We seek scaling factors to the monthly a priori emissions on the $2^{\circ} \times 2.5^{\circ}$ GEOS-Chem grid that are most consistent with the observed wet deposition $\mathrm{NH}_{4}^{+}$fluxes, accounting for errors in both model and observations by Bayesian optimization. This is accomplished by minimizing the least squares scalar cost function $(\mathcal{J})$

$$
\mathcal{J}=\frac{1}{2}\left(\mathbf{M} \mathbf{f}_{\text {sim }}-\mathbf{f}_{\text {obs }}\right)^{T} \mathbf{S}_{\text {obs }}^{-1}\left(\mathbf{M} \mathbf{f}_{\text {sim }}-\mathbf{f}_{\text {obs }}\right)+\frac{1}{2} \boldsymbol{\eta}^{T} \mathbf{S}_{a}^{-1} \boldsymbol{\eta}
$$

where $\mathbf{f}_{\text {obs }}$ and $\mathbf{f}_{\text {sim }}$ designate the ensemble of observed monthly wet deposition fluxes of $\mathrm{NH}_{4}^{+}$and the collocated model values, $\mathbf{S}_{\text {obs }}$ is the error covariance matrix of the observation system, $\mathbf{S}_{a}$ is the error covariance matrix of the a priori $\mathrm{NH}_{3}$ emissions, $\mathbf{M}$ is the precipitation correction matrix discussed below, and $\boldsymbol{\eta}$ is a vector of log-normal scaling factors on the $2^{\circ} \times 2.5^{\circ}$ grid with elements $\eta_{i}=\ln \left(E_{i} / E_{a, i}\right)$, where $E_{i}$ and $E_{a, i}$ are the corresponding optimized and a priori $\mathrm{NH}_{3}$ emissions for grid square $i$. Optimizing the logarithm of emissions (with corresponding assumption of log-normally distributed errors) accommodates the requirement of positivity [Tarantola, 2005]. Minimization of $\mathcal{J}$ by solving $\nabla_{\eta} \mathcal{J}$ provides a best (optimized) estimate of $E_{i}$. 


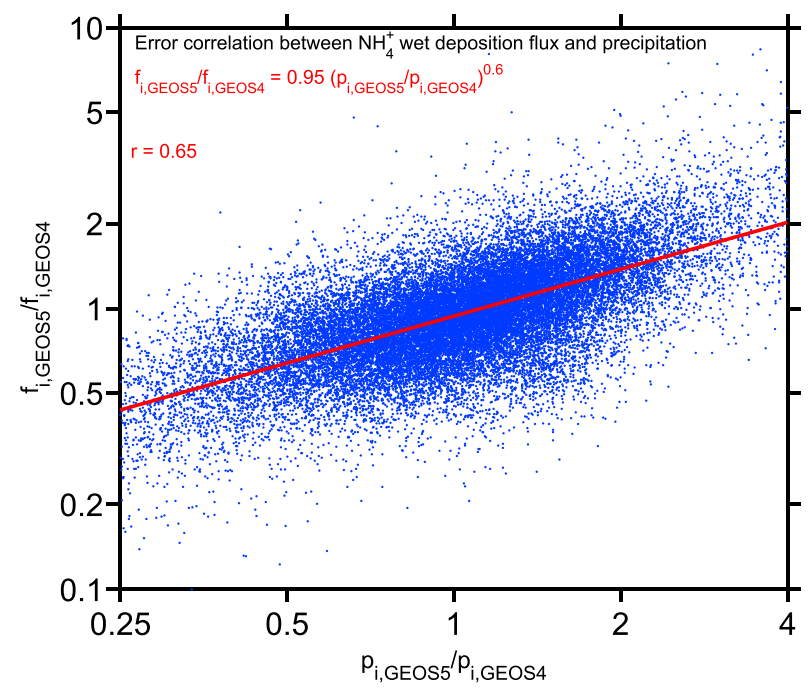

Figure 1. Error correlation between the monthly $\mathrm{NH}_{4}^{+}$wet deposition flux $\left(f_{i}\right)$ and monthly surface precipitation $\left(p_{i}\right)$, as derived from GEOS-Chem simulations from July 2005 to July 2006 using two different assimilated meteorological data fields (GEOS-5 and GEOS-4) for the same meteorological year. Each point represents monthly data for a $2^{\circ} \times 2.5^{\circ} \mathrm{GEOS}-\mathrm{Chem}$ grid square. Only land grid squares with $\mathrm{NH}_{4}^{+}$ wet deposition fluxes greater than $0.017 \mathrm{~kg} \mathrm{~N} \mathrm{ha}^{-1} \mathrm{month}^{-1}$ are considered. The ratio of monthly GEOS-5 to GEOS- $4 \mathrm{NH}_{4}^{+}$wet deposition flux is plotted against the corresponding ratio of precipitation amounts. The regression line and correlation are shown in the inset.

and the regression line provides a parameterized relationship between error in precipitation and error in the $\mathrm{NH}_{4}^{+}$wet deposition flux. We use this relationship to account for the difference between observed and simulated precipitation, such that

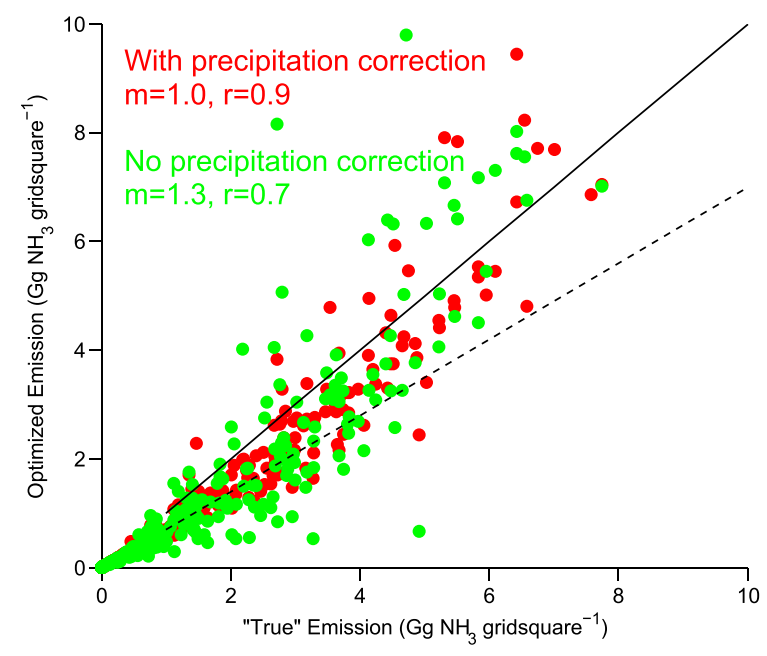

Figure 2. Effect of precipitation correction (equation (2)) on the adjoint optimization of $\mathrm{NH}_{3}$ emissions on the $2^{\circ} \times 2.5^{\circ} \mathrm{GEOS}$-Chem grid, as diagnosed by a paired model test. In this test, "true" emissions were defined as the global inventory of Table 1, and prior emissions were taken to be biased low globally by $30 \%$ (dashed line). Pseudo NADP observations based on the true emission were generated using the GEOS-4 meteorological fields, and the adjoint optimization of emissions based on these observations was driven by the GEOS- 5 meteorological fields, with and without the precipitation correction. Each symbol represents July emissions for a U.S. grid square. Regression slope $(m)$ and correlation coefficient $(r)$ are indicated for each optimization. The solid line is the 1:1 line.
Gilliland et al. [2006] and Pinder et al. [2006] showed that model errors in precipitation could propagate to errors in the simulated $\mathrm{NH}_{4}^{+}$wet deposition fluxes, affecting the results of the inversion. Here we estimate this effect by conducting GEOS-Chem simulations ical data sets, GEOS-4 and GEOS-5, for the same meteorological year. These two data sets are both produced by the NASA Global Modeling and Assimilation Office but use different underlying general circulation models, including different convective schemes and different meteorological data assimilation methods. We keep emissions identical in both simulations such that differences in simulated $\mathrm{NH}_{4}^{+}$wet deposition flux are solely caused by differences in meteorology. Figure 1 shows the relationship between $p_{\mathrm{GEOS} 5, \mathrm{i}} / p_{\mathrm{GEOS} 4, \mathrm{i}}$ and $f_{\mathrm{GEOS} 5, \mathrm{i}} / f_{\mathrm{GEOS} 4, \mathrm{i}}$, where $p_{i}$ is the monthly surface precipitation for an individual grid square $i$. It describes the error correlation between $\boldsymbol{f}$ and $\boldsymbol{p}$, and the regression line provides a param$\mathbf{M}=\left(m_{i, j}\right)$ is a diagonal matrix with elements

$$
m_{i, i}=\left(\frac{p_{\mathrm{obs}, i}}{p_{\mathrm{sim}, i}}\right)^{0.6}
$$

where $p_{\mathrm{obs}, i}$ is the monthly observed surface precipitation and $p_{\text {sim }, i}$ is the corresponding model value. Only observations with $0.25<\frac{p_{\text {obs }, i}}{p_{\text {sim }, i}}<4$ are considered in order to limit the effect of this correction.

We evaluate the effect of the precipitation correction on the optimization using pseudo NADP observations generated using a GEOS-Chem simulation driven by GEOS-4 meteorological data. Here $\boldsymbol{\eta}$ is optimized using the adjoint of GEOS-Chem driven by GEOS- 5 meteorological data. Figure 2 shows that the precipitation correction from equation (2) has a large effect on the optimized emissions. In this test we find that our precipitation correction (equation (2)) removes the bias, although this reflects in part the use of the same pair of models to generate the correction statistics and carry out the pseudo-inversion. with two different driving meteorolog- 

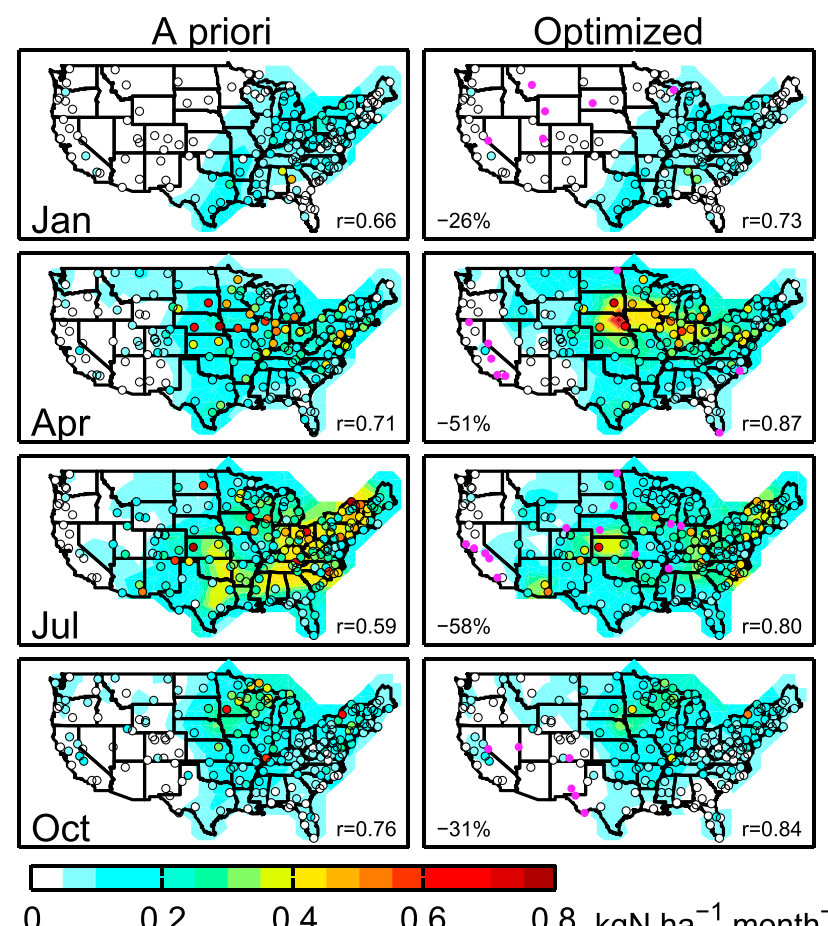

0

0.2

0.4

0.6

$0.8 \mathrm{kgN} \mathrm{ha}^{-1}$ month $^{-1}$

Figure 3. Monthly $\mathrm{NH}_{4}^{+}$wet deposition fluxes for 2006 over the U.S. measured at NADP sites (circles) and simulated by GEOS-Chem (left) before optimization of $\mathrm{NH}_{3}$ emissions and (right) after optimization. In Figure 3 (right), NADP observations are multiplied by $\mathbf{M}^{-1}$ to account for the precipitation difference between model and observations as given by (2). Purple circles indicate NADP sites where the model precipitation deviates from observations by more than a factor of 4 and are therefore not used in the inversion. We also show for each panel the correlation coefficient $(r)$ between model and observations, and the change in the mean absolute bias between observed and simulated $\mathrm{NH}_{4}^{+}$ wet deposition. the precipitation effect (according to equation (2)). The resulting model error is estimated to be $(0.2 \mathrm{~kg} \mathrm{~N}$ $\mathrm{ha}^{-1} \mathrm{a}^{-1} \pm 20 \%$ ) and can be visualized as the noise about the regression line in Figure 1 .

Errors in the representation of dry deposition in GEOS-Chem, including the effect of bidirectional exchange [Personne et al., 2009; Massad et al., 2010; Bash et al., 2013], can affect the results of the inversion. Regions where dry deposition largely dominates deposition (e.g., the arid U.S. Southwest) will not be discussed in this study, as they are poorly constrained by our inversion. Bidirectional exchange of $\mathrm{NH}_{3}$ extends the effective footprint of the source-receptor relationship for $\mathrm{NH}_{4}^{+}$deposition but a proper representation would require tracking of nitrogen in the soil from deposition to reemission. We assume here that most of the observed variability in $\mathrm{NH}_{4}^{+}$wet deposition is driven by primary $\mathrm{NH}_{3}$ emissions rather than reemissions.

The structure of the a priori error covariance matrix is best estimated by propagation of errors in the bottom-up inventory but we do not have this information available. Previous studies [Hutchings et al., 2001; Pinder et al., 2004b, 2011; Skjøth et al., 2011] have shown that agricultural emission types often vary on scales much smaller than our $2^{\circ} \times 2.5^{\circ}$ grid. However, the approaches used to estimate $\mathrm{NH}_{3}$ emissions would likely lead to spatial correlations in the errors. We do not consider those here as the error structure is unknown. Hence, $\mathbf{S}_{a}$ is diagonal, similar to previous inversions of $\mathrm{NH}_{3}$ emissions [Henze et al., 2009; Zhu et al., 2013]. Having nondiagonal terms in the $\mathbf{S}_{a}$ matrix would potentially increase the overall uncertainties in the inversion.

Recent studies have shown that current $\mathrm{NH}_{3}$ emission inventories have large errors in parts of the U.S., including Colorado [Heald et al., 2012], California [Nowak et al., 2012; Walker et al., 2012; Zhu et al., 2013], and the U.S. Midwest [Fisher et al., 2011; Zhang et al., 2012]. Here we assume a factor of 3 uncertainty for the U.S. and Europe on the $2^{\circ} \times 2.5^{\circ}$ grid, similar to Zhu et al. [2013]. In China, Huang et al. [2012] found large 

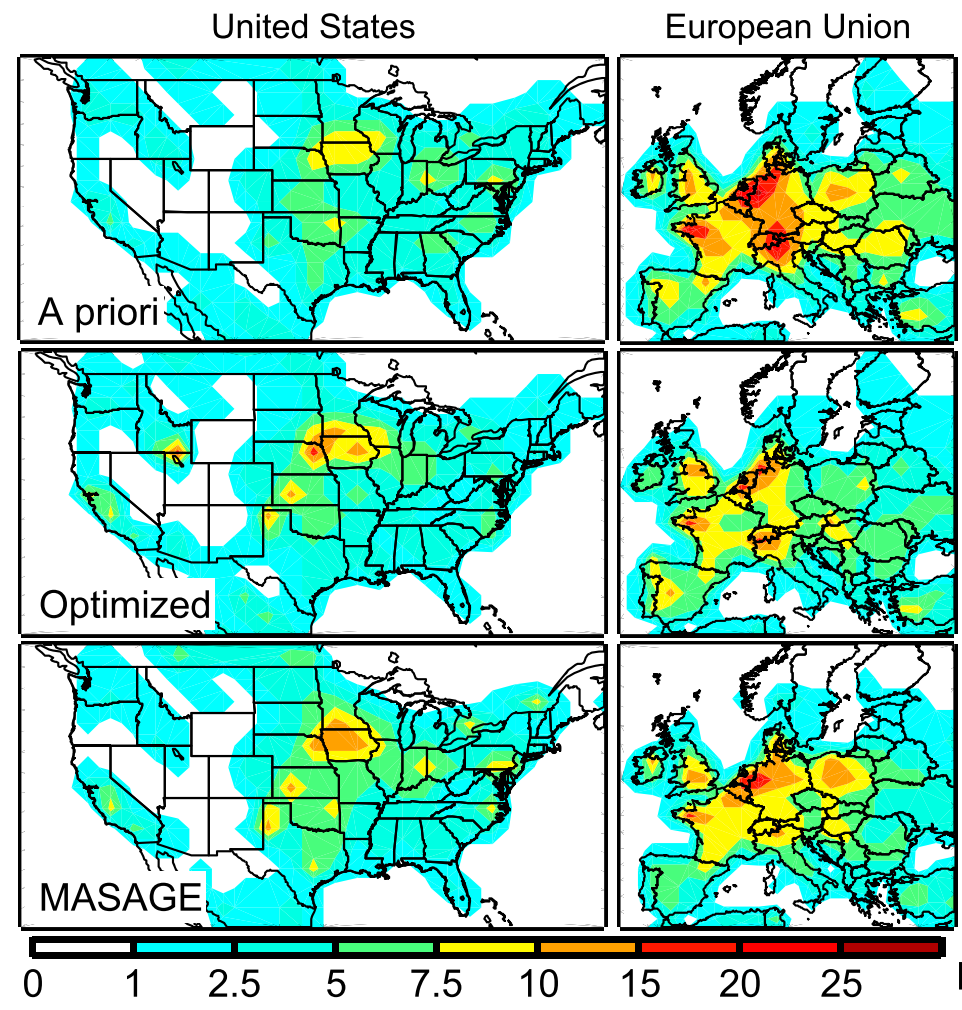
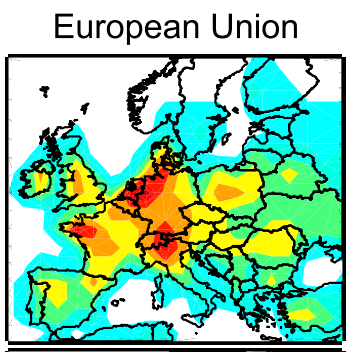

East Asia (x 0.5)
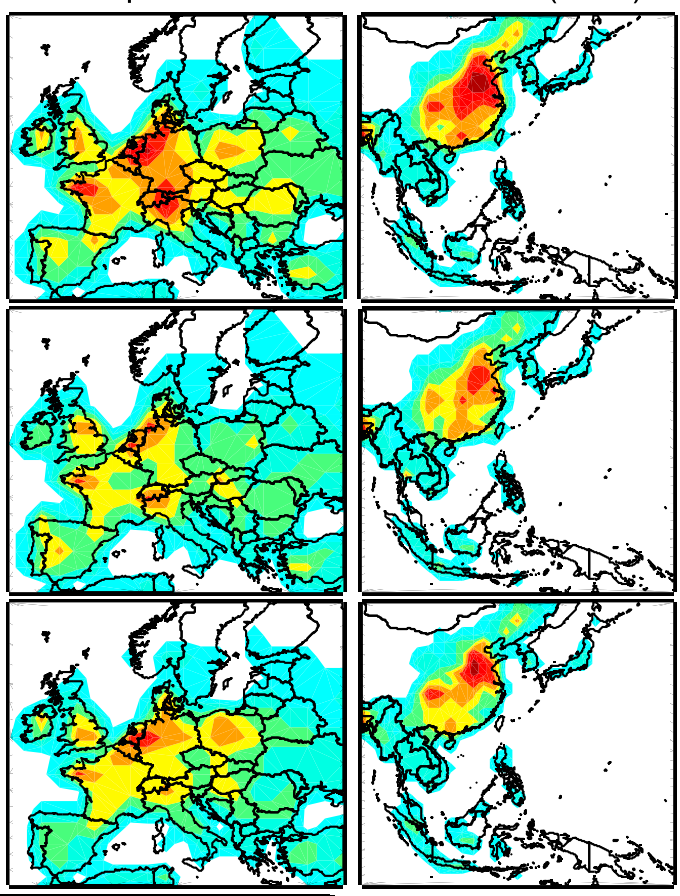

$\mathrm{kg}\left(\mathrm{NH}_{3}-\mathrm{N}\right) \mathrm{ha}^{-1} \mathrm{a}^{-1}$

Figure 4. Annual $\mathrm{NH}_{3}$ emissions in the contiguous U.S., Europe, and East Asia. The a priori emissions in (top) GEOS-Chem, (middle) the optimized emissions from the adjoint inversion, and (bottom) the emissions from the MASAGE_NH3 inventory. Values are averages for the 2005-2008 period. Asian emissions are divided by two to fit on the color scale.

disagreement regarding the magnitude of $\mathrm{NH}_{3}$ at the national scale, and we therefore assume a factor of 6 uncertainty on the $2^{\circ} \times 2.5^{\circ}$ grid there. To test the sensitivity to these assumed errors, we also conducted an inversion with a factor of 5 uncertainty over the U.S. and Europe and a factor of 9 uncertainty over China. Total annual optimized emissions change by less than $2 \%$ in each region. The a priori thus plays little role in the inversion.

The adjoint optimization minimizes $\mathcal{J}$ iteratively using the quasi-Newton L-BFGS-B optimization routine [Byrd et al., 1994; Zhu et al., 1997; Henze et al., 2009], with $\nabla_{\eta} \mathcal{J}$ calculated numerically using the adjoint of the GEOS-Chem model (version 31) [Henze et al., 2007; Paulot et al., 2013]. For computational reasons, we conduct the inversion month by month, optimizing $\boldsymbol{\eta}$ in the month considered and the week proceeding it. We find that 20 iterations are sufficient in all cases to achieve convergence, as defined by change in $\mathcal{J}$ of less than $1 \%$ from one iteration to the next. Depending on the month, $\mathcal{J}$ is reduced between $33 \%$ and $84 \%$, and $\nabla_{\eta} \mathcal{J}$ is reduced by $98 \%$ or more, similar to previous adjoint model-based inversion [Henze et al., 2009; Zhu et al., 2013].

\section{Results and Discussion}

\subsection{United States}

Figure 3 compares modeled and observed $\mathrm{NH}_{4}^{+}$wet deposition fluxes over the contiguous U.S. before (Figure 3, left) and after (Figure 3, right) optimization. Observations are multiplied by $\mathbf{M}^{\mathbf{- 1}}$ (see equation (2)) in Figure 3 (right) to account for differences between simulated and observed precipitation. Observed $\mathrm{NH}_{4}^{+}$wet deposition is maximum in spring and summer and peaks in the Midwest. After optimization, the correlation ( $r$ ) between model and observation improves for all months and the mean absolute bias between observed and simulated $\mathrm{NH}_{4}^{+}$is reduced by up to $60 \%$. Optimized annual emissions of $\mathrm{NH}_{3}$ over the contiguous U.S. are $2.8 \mathrm{Tg} \mathrm{NH}_{3}-\mathrm{N} \mathrm{a}^{-1}$, not significantly different from the a priori or from previous estimates (Table 1). However, the spatial and seasonal distributions (Figures 4 and 5) show large differences. We elaborate on these differences below. 


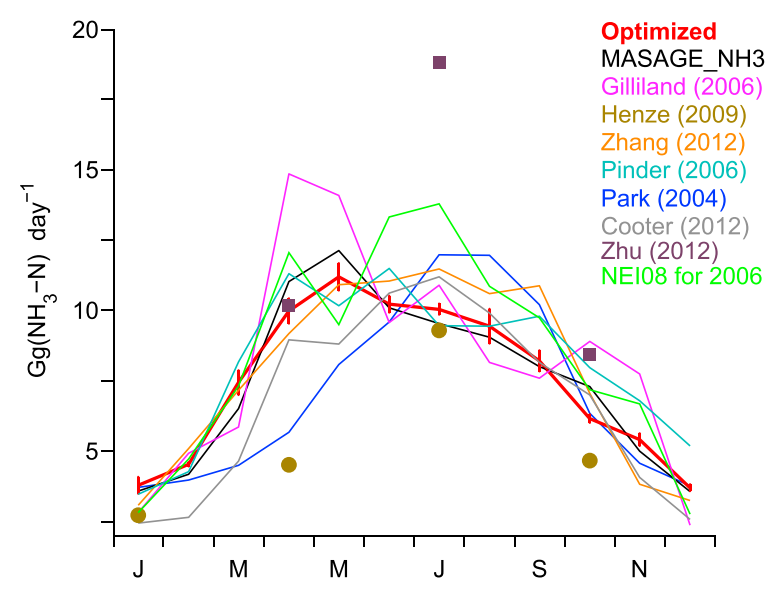

Figure 5. Estimates of total $\mathrm{NH}_{3}$ emissions in the contiguous U.S. and their seasonal variation. Our optimized estimate from the adjoint inversion of $\mathrm{NH}_{4}^{+}$wet deposition fluxes is compared to the MASAGE_NH3 bottom-up inventory (this work) and to previous estimates from the literature including bottom-up inventories (Park et al. [2004], Pinder et al. [2006], Cooter et al. [2012], and NEI08 (http://www.epa.gov/ttnchie1/net/2008inventory.html)) and inverse analyses (Gilliland et al. [2006], Zhang et al. [2012], and Zhu et al. [2013]). The 2005-2008 interannual variability of our monthly optimized $\mathrm{NH}_{3}$ emissions is indicated by red bars (one standard deviation). The GEOS-Chem a priori is based on Park et al. [2004]. trated animal feeding operations [Hristov et al., 2011]. The a priori underestimate in the Midwest, previously noted in GEOS-Chem simulations [Fisher et al., 2011; Zhang et al., 2012], is explained here by $\mathrm{NH}_{3}$ emissions
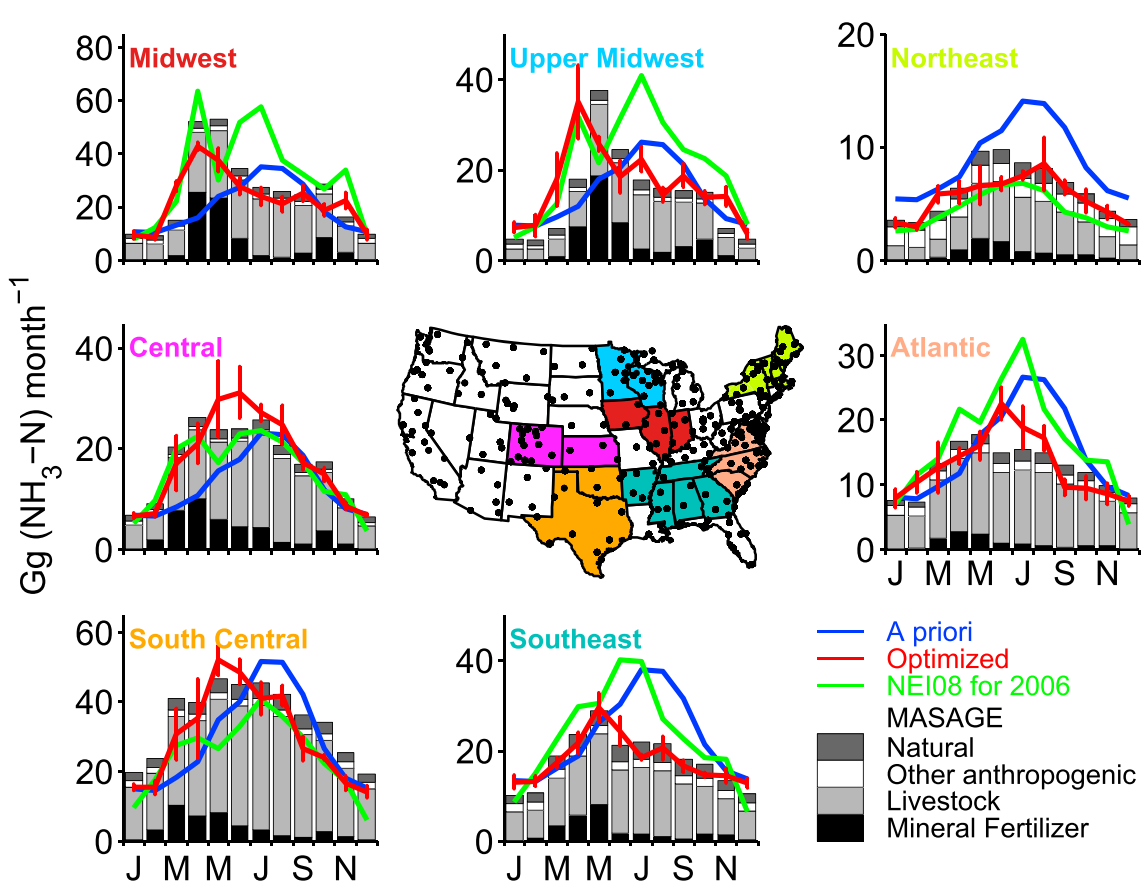

Figure 6. Seasonality of $\mathrm{NH}_{3}$ emissions in different regions of the United States. The optimized emission inventory from the adjoint inversion (red lines) is compared to the MASAGE_NH3 bottom-up inventory (stacked histogram). The a priori estimate for the inversion based on EPA NEI05 with seasonality from Park et al. [2004] is also shown (blue line) and the EPA NEI08 emissions (green line). The 2005-2008 interannual variability of the monthly optimized $\mathrm{NH}_{3}$ emissions is indicated by the thin red bar (one standard deviation). Note the differences in scale between panels. 

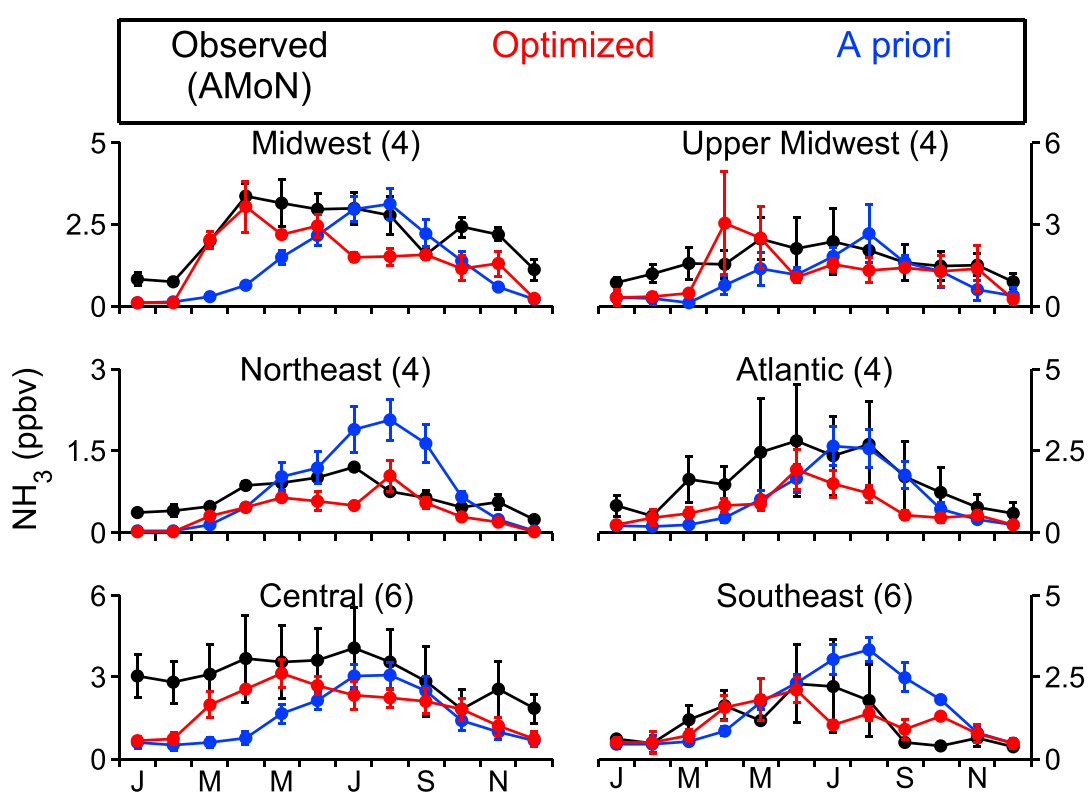

Figure 7. Seasonal variations of gaseous $\mathrm{NH}_{3}$ concentrations in surface air for the U.S. regions shown in Figure 6. Twenty four hour observations from the AMoN sites are averaged monthly from 2007 to 2012 . The number of sites in each region is given in parentheses. Simulated $\mathrm{NH}_{3}$ using a priori or optimized emissions and sampled the same sites is averaged. Simulated $\mathrm{NH}_{3}$ is averaged monthly from 2005 to 2008. The interannual variability is indicated by the vertical bars (one standard deviation). Measurements were converted to $\mathrm{ppbv}$ from ${ }^{-} \mathrm{g} \mathrm{m}^{-3}$ assuming standard ambient temperature and pressure $\left(T=298.15 \mathrm{~K}\right.$ and $\left.P=10^{5} \mathrm{~Pa}\right)$.

associated with fertilizer application. However, the MASAGE_NH3 inventory does not capture well the large emissions in southern Idaho, where the dominant source of $\mathrm{NH}_{3}$ is dairy cattle.

Figure 5 compares the average seasonality of the optimized and MASAGE $\mathrm{NH}_{3}$ emissions over the contiguous U.S. with previously published estimates from bottom-up inventories (Park et al. [2004], Pinder et al. [2006], Cooter et al. [2012], and NEI08) and inverse analyses (Gilliland et al. [2006], Henze et al. [2009], Zhang et al. [2012], and Zhu et al. [2013]). Also shown in Figure 5 is the 2005-2008 interannual variability of our optimized emissions. This reflects not only true variability but also changes in data availability. It is relatively small (10\%) and does not affect seasonality.

The annual emission in the contiguous U.S. averaged across all estimates is $2.8 \pm 0.2 \mathrm{Tg} \mathrm{NH}_{3}-\mathrm{N} \mathrm{a}^{-1}(2 \sigma)$. All studies find that $\mathrm{NH}_{3}$ emissions are minimum in winter. They diverge regarding the timing of the seasonal maximum. Several studies based on bottom-up [Park et al., 2004; Cooter et al., 2012] or top-down constraints [Henze et al., 2009; Zhang et al., 2012; Zhu et al., 2013] find a summer peak reflecting a dominant influence of livestock housing emissions. Other bottom-up inventories [Goebes et al., 2003; Pinder et al., 2006] imply an April-June peak more consistent with our work (MASAGE_NH3 and optimized) and reflecting an important contribution from mineral fertilizer and manure application in spring. The NEI08 inventory features both a spring and summer peak. The top-down inventory of Gilliland et al. [2006] based on ammonium wet deposition fluxes features a very large April-May maximum and a prominent secondary maximum in October-November, but the authors point out that this could partly be due to biases in their model precipitation. The high summer emissions inferred from optimization of TES satellite data for $\mathrm{NH}_{3}$ at 1330 local time could be caused by the lack of diurnal cycle in GEOS-Chem $\mathrm{NH}_{3}$ emissions or to biases in $\mathrm{NO}_{3 T}$ [Zhu et al., 2013]. Zhu et al. [2013] found that these TES-optimized emissions cannot be reconciled with observed wet deposition from NADP and surface air $\mathrm{NH}_{3}$ concentrations from the Ammonia Monitoring Network (AMoN) [Puchalski et al., 2011].

Figure 6 further analyzes $\mathrm{NH}_{3}$ emission seasonality in different regions of the United States. Emissions in the Midwest and upper Midwest peak in April, whereas they peak in May-June in the rest of the United States. The MASAGE_NH3 model (Figure 6, bars) indicates that this heterogeneity stems from differences in the seasonalities of manure and fertilizer emissions. Heald et al. [2012] also noted the need to treat separately manure and fertilizer sources of $\mathrm{NH}_{3}$ to capture the seasonality of $\mathrm{NH}_{3}$ emissions in Colorado and Wyoming. 

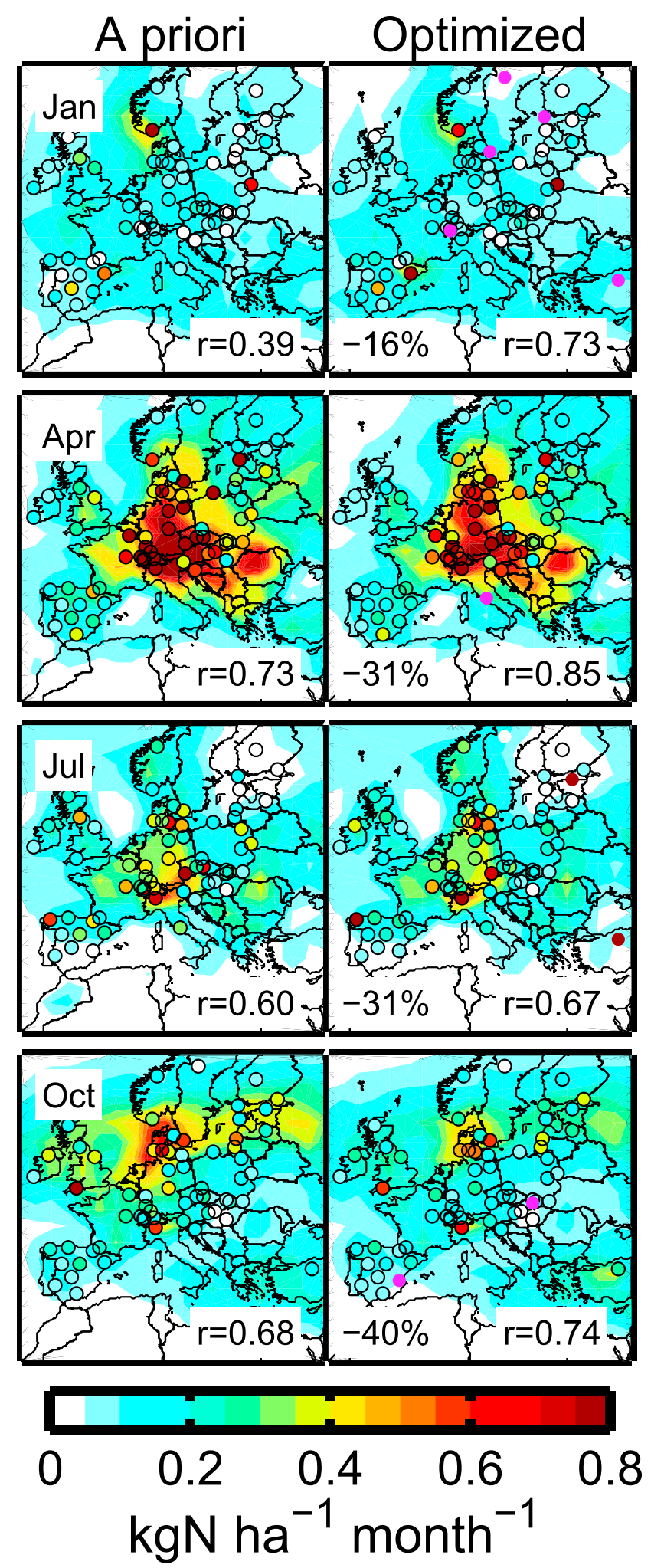

Figure 8. Same as Figure 3 but for Europe with observations from the EMEP network.
In the Southeast and Central U.S. (as defined in Figure 6), the MASAGE_NH3 inventory indicates that emissions are dominated by manure from cattle. Fertilizer emissions are spread over a longer time period than in the upper Midwest reflecting the different planting dates for cotton, corn, and winter wheat. In the Atlantic region, MASAGE_NH3 underestimates summer emissions, which are dominated by hog manure in the model. In the Northeast, the MASAGE_NH3 inventory is consistent with the optimized emissions and lower emissions than the a priori, which is based on NEI05. The overestimate of emissions in NEI05 could be associated with the use of biofuels for residential heating, mobile sources, and the abandonment of agriculture [Drummond and Loveland, 2010].

In the Midwest, the seasonality is dominated by fertilizer application at corn planting, although manure emissions (mostly from hog and beef manure) dominate the annual total. The MASAGE_NH3 model seasonal peak lags by 1 month suggesting different fertilizer application dates. Timing and magnitude of the spring peak are consistent with the NEI08 inventory. However, our optimized emissions are $50 \%$ lower than the NEI08 inventory in summer.

Figure 7 compares observed and simulated surface air $\mathrm{NH}_{3}$ concentrations at AMoN sites [Puchalski et al., 2011], providing an independent test of the inversion. Observations are aggregated following the regions shown in Figure 6. After optimization, GEOS-Chem better captures the seasonality and magnitude of the observations in the Northeast and Southeast regions, consistent with an overestimate of $\mathrm{NH}_{3}$ emissions in both regions in the NEI05 inventory. In the Midwest and upper Midwest, the optimized model captures the spring enhancement in the AMoN data but underestimates $\mathrm{NH}_{3}$ summertime concentrations. This discrepancy in the summertime could reflect in part the absence of bidirectional exchange of $\mathrm{NH}_{3}$ between the surface and the atmosphere in the model, which results in an underestimate of the lifetime of atmospheric $\mathrm{NH}_{3}$ [Wichink Kruit et al., 2012]. In the Atlantic and Central regions, the optimized model is too low and in particular does not capture the high values in the Central region in winter. Some 

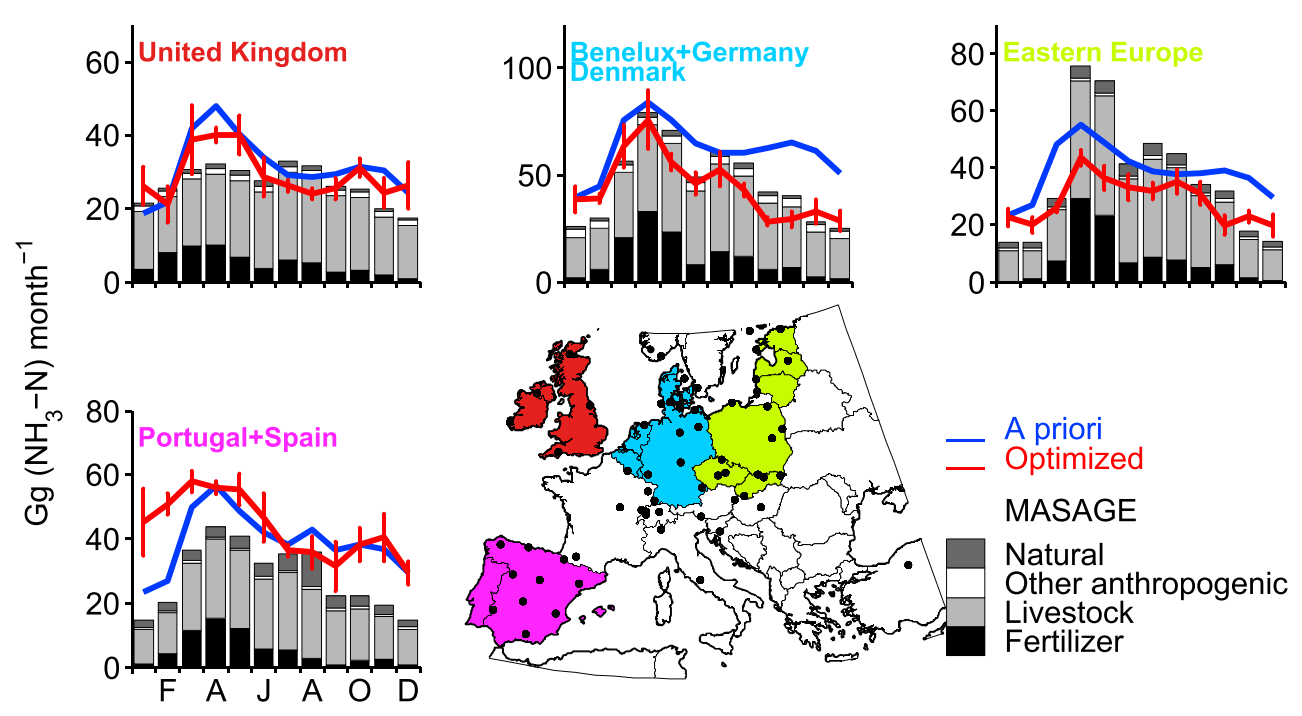

Figure 9. Same as Figure 6 but for Europe.

caution is needed in interpreting these comparisons, because the AMoN data are $24 \mathrm{~h}$ averages and the model does not properly capture the nighttime stratification if only because of the coarse vertical grid. This would result in positive or negative bias depending on whether $\mathrm{NH}_{3}$ deposition or emissions dominate locally.

\subsection{European Union}

Figure 8 compares simulated and observed $\mathrm{NH}_{4}^{+}$wet deposition fluxes in Europe. Unlike in the U.S., there is a clear spring maximum with much lower summer values. After optimization, the correlation improves in particular in the winter and the mean absolute bias between observed and simulated $\mathrm{NH}_{4}^{+}$wet deposition is reduced by $15 \%$ to $40 \%$. The adjoint optimization decreases annual total $\mathrm{NH}_{3}$ emissions in the European Union by $17 \%$ relative to the GEOS-Chem a priori (Table 1), to a value within $5 \%$ of the EMEP inventory. The MASAGE_NH3 inventory is also consistent with this decrease. Since the GEOS-Chem a priori for anthropogenic sources is based on EMEP, this discrepancy may reflect an overestimate of natural sources also included in the a priori.

Figure 4 shows that the adjoint optimization reduces emissions throughout Europe. The largest decrease is in the Benelux, Denmark, and Germany. Under the Gothenburg protocol (http://www.unece.org/env/lrtap/ multi_h1.html), Denmark, Belgium, and Netherlands committed to decreasing their $\mathrm{NH}_{3}$ emissions to $40 \%$ of their 1990 levels by 2010. The optimization suggests that efforts to curb $\mathrm{NH}_{3}$ emissions have been successful in this region. This was primarily achieved via a reduction in livestock number, lower fertilizer application, and improved management of manure [Indicator Reporting on the Integration of Environmental Concerns into Agriculture Policy, 2005].

Unlike other European countries, Spain did not commit to a reduction of its emissions under the Gothenburg protocol and we find no decrease of $\mathrm{NH}_{3}$ emissions in this region relative to the a priori. MASAGE_NH3 underestimates $\mathrm{NH}_{3}$ emissions there and this may by driven by hog farming, the largest $\mathrm{NH}_{3}$ source in the region. Rebolledo et al. [2013] used an emission factor of $6.9 \mathrm{~kg}\left(\mathrm{NH}_{3}\right) \mathrm{head}^{-1} \mathrm{a}^{-1}$ for hogs, while the MASAGE_NH3 emission factor derived from GAINS is $4.3 \mathrm{~kg}\left(\mathrm{NH}_{3}\right)$ head $^{-1} \mathrm{a}^{-1}$.

Figure 9 shows the seasonality of the optimized $\mathrm{NH}_{3}$ emissions in different European countries. This seasonality is spatially more homogeneous than in the U.S., which may reflect diversified food production systems (crop+livestock) at the national scale. Similar to the a priori seasonality [Friedrich and Reis, 2004], the optimized emissions in the European Union peak in April, whereas national U.S. emissions peak in May (Figure 9). MASAGE_NH3 suggests that this difference is driven by different manure management practices, which result in a greater fractional contribution of manure application in the European Union. Optimized emissions are particularly reduced relative to the a priori (EMEP) in Benelux, Denmark, and Germany in the fall. This reduction is consistent with regulation prohibiting farmers from spreading manure outside of the growing 
A priori Optimized
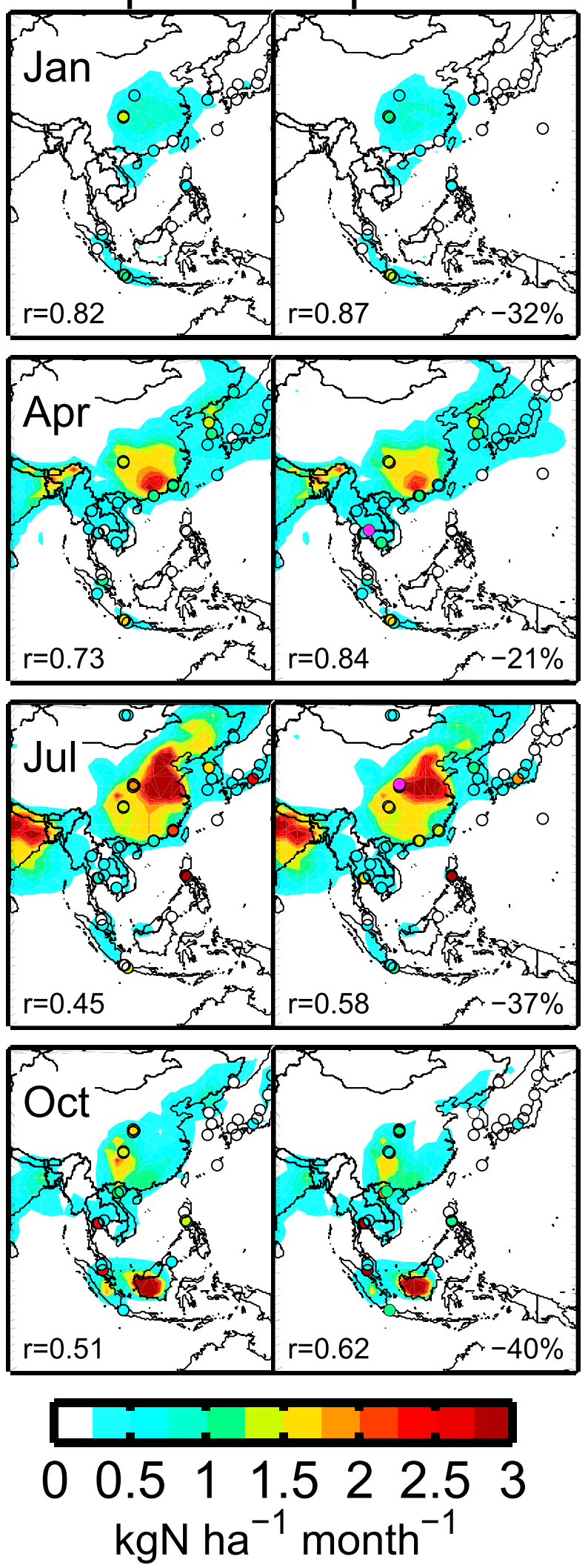

Figure 10. Same as Figure 3 but for East Asia with observations from the EANET network. season to reduce $\mathrm{N}$ losses [Skjøth et al., 2008]. The seasonality of emissions in the United Kingdom is excessively muted by MASAGE_NH3. We find that this is caused by fertilizer application to winter wheat in January-March in the model triggered by mild winter temperatures. Such early applications are inconsistent with observations (http:// www.ukagriculture.com/production_ cycles/wheat_production_cycle.cfm).

\subsection{China}

Figure 10 shows observed and simulated $\mathrm{NH}_{4}^{+}$wet deposition in East Asia. We focus our analysis on China, where $\mathrm{NH}_{3}$ emissions have doubled since 1980 according to Liu et al. [2013]. The magnitude of Chinese $\mathrm{NH}_{3}$ emissions is almost twice as large as the combined emissions of the European Union and the U.S. (Table 1), as reflected by the high observed $\mathrm{NH}_{4}^{+}$deposition fluxes in the region (Figure 10) [Liu et al., 2013]. Our optimized emission in China is $8.4 \mathrm{Tg} \mathrm{NH}_{3}-\mathrm{N}^{-1}$, which is $25 \%$ lower than the recent inventories of Streets et al. [2003] and Liu et al. [2013] but similar to that of [Huang et al. 2012].

Figure 11 shows the seasonality of emissions in China. Our optimized emissions peak in June-July, similar to previous estimates [Streets et al., 2003; Huang et al., 2012]. Observations from the TES satellite also support a summer maximum of $\mathrm{NH}_{3}$ emissions in China [Shephard et al., 2011]. This difference with the seasonality of $\mathrm{NH}_{3}$ emissions in the U.S. and the European Union may reflect different fertilizer application practices. In particular, corn, which accounts for $16 \%$ of fertilizer usage in China [Heffer, 2009], is often planted in summer after winter wheat is harvested [Huang et al., 2012]. Optimized emissions differ most from the a priori in summer (June emissions are reduced by $40 \%)$. The contrast between winter 


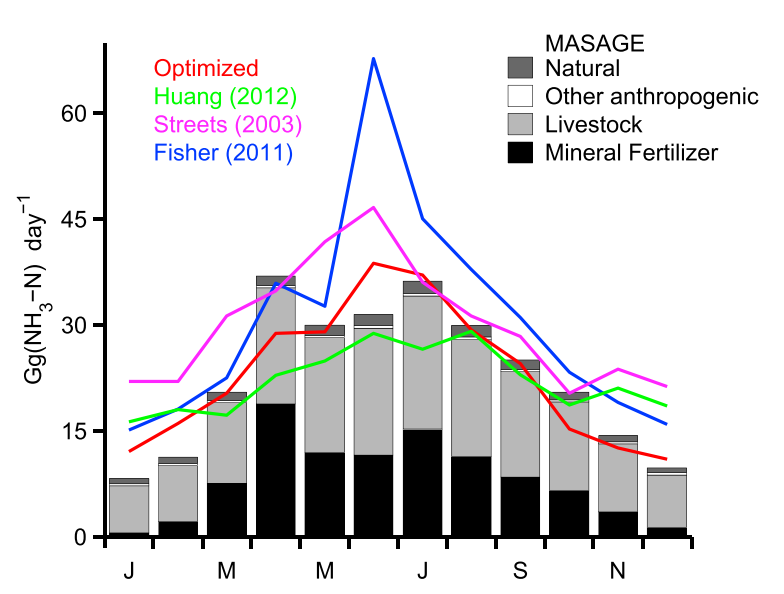

Figure 11. Seasonality of $\mathrm{NH}_{3}$ emissions in China. The optimized emission inventory from the adjoint inversion is compared to our MASAGE_NH3 bottom-up inventory and to two bottom-up inventories [Streets et al., 2003; Huang et al., 2012]. The GEOS-Chem a priori is based on the Streets et al. [2003] inventory but uses a different seasonality [Fisher et al., 2011]. and summer is reduced but remains greater than calculated by [Huang et al. 2012].

The MASAGE_NH3 inventory needs to be adjusted to capture the seasonality of Chinese emissions. We force corn to be planted after winter wheat harvest to account for double cropping and we reduce fertilizer emissions by $25 \%$. Huang et al. [2012] showed that a detailed treatment of fertilizer emissions factors ( $\alpha_{c}$ in equation (A1)) decreases estimated Chinese emissions from mineral fertilizer by more than $50 \%$ compared to Streets et al. [2003]. MASAGE_NH3 fertilizer emissions are $15 \%$ greater than the estimate of Huang et al. [2012]. Other uncertainties include the magnitude and seasonality of fertilizer application to fruit and vegetable crops, pasture, and forests, which is estimated to account for $40 \%$ of mineral fertilizer consumption in China [Heffer, 2009].

\section{Conclusions}

We used the adjoint of the GEOS-Chem chemical transport model to optimize $\mathrm{NH}_{3}$ emissions in the U.S., European Union, and China by inversion of 2005-2008 monitoring network data for $\mathrm{NH}_{4}^{+}$wet deposition fluxes from NADP (U.S.), CAPMoN (Canada), EMEP (Europe), and EANET (Asia). We compared the optimized results from the adjoint inversion to standard emission inventories (NEI, EMEP, Streets et al. [2003]) used as a priori in GEOS-Chem. We also developed a new bottom-up emission inventory, MASAGE_NH3, which incorporates sector-resolved information for agricultural activities on a global scale. We used this inventory to interpret the optimized estimates of $\mathrm{NH}_{3}$ emissions from the adjoint inversion in terms of the underlying processes.

Wet deposition fluxes are closely related to emissions by mass balance, and the monitoring networks provide high-density data to constrain adjoint inversions at least for the U.S. and Europe. Model biases in precipitation can be a source of error, since there is competition between wet and dry deposition (40\% of $\mathrm{NH}_{3}$ deposition to the contiguous U.S. in GEOS-Chem is by dry deposition). Here we estimated and corrected for this error by conducting GEOS-Chem simulations for the same meteorological year but with different assimilated meteorological fields. A drawback of the adjoint method is that error statistics on the solution are not generated as part of the inversion, unlike for an analytical inversion; but such error statistics tend to be too small in any case [Arellano and Hess, 2006] due to the assumptions of random errors and representative sampling of the error distribution functions. An ensemble of inversions can provide a better error characterization [Heald et al., 2004] but was not computationally practical here.

U.S. optimized emissions are $2.8 \mathrm{Tg} \mathrm{NH}_{3}-\mathrm{N} \mathrm{a}^{-1}$. We show that annual total U.S. emissions agree within $10 \%$ for a range of bottom-up and top-down emissions in the literature. However, regional and seasonal distributions show greater differences. Based on MASAGE_NH3, we find that the distribution of emissions follows that of fertilizer-intensive agriculture (in particular corn) and of animal feeding operations. Seasonality is consistent with fertilizer emissions peaking in spring and manure emissions peaking in summer. This contrast explains the different seasonality of the Midwest (peak at corn planting in spring) and the rest of the United States. Previous GEOS-Chem studies underestimated $\mathrm{NH}_{3}$ emissions in the Midwest, and we show that this reflects inadequate accounting of fertilizer emissions.

Optimized emissions in the European Union are 3.1 $\mathrm{Tg} \mathrm{NH}_{3}-\mathrm{N} \mathrm{a}^{-1}$, consistent with the EMEP inventory. Seasonality of emissions is more homogeneous across the European Union than in the U.S., which we attribute to diversified food production at the national level. Unlike in the U.S., the seasonality of emissions in the 
Europe Union has a consistent spring peak that we attribute to different manure management practices. Our optimized emissions in fall are much lower than the a priori for north-central Europe and we attribute this to new regulations to reduce $\mathrm{NH}_{3}$ emissions by restricting manure spreading. Unlike other European countries, Spain did not commit to an emission reduction under the Gothenburg protocol and our work suggests that Spanish emissions have not been reduced.

In China, our optimized $\mathrm{NH}_{3}$ emission is $8.4 \mathrm{Tg} \mathrm{NH}_{3}-\mathrm{N} \mathrm{a}^{-1}$. This is similar to a recent bottom-up inventory by Huang et al. [2012] but 25\% lower than the inventory of Streets et al. [2003]. Unlike in the U.S. and European Union, emissions peak in summer even though fertilizer application accounts for a larger fraction of Chinese agricultural emissions (40-60\%). We attribute this seasonality to double cropping, resulting in the application of mineral fertilizer and manure to corn in summer.

The MASAGE_NH3 global inventory of $\mathrm{NH}_{3}$ emissions reproduces the major features of our adjoint optimization, including spatial and seasonal variability. It provides global information for a range of agricultural processes (see Table A1), which could be included in chemical transport models. MASAGE_NH3 may also be used to calculate the seasonality of agricultural $\mathrm{NH}_{3}$ emissions, when only annual totals are provided such as for future $\mathrm{NH}_{3}$ emissions from the Representative Concentration Pathways.

Global agricultural emissions of $\mathrm{NH}_{3}$ are estimated to be $34 \mathrm{Tg} \mathrm{NH}_{3}-\mathrm{N} \mathrm{a} \mathrm{a}^{-1}$ ( $63 \%$ of the total $\mathrm{NH}_{3}$ emissions). MASAGE_NH3 suggests that $\sim 60 \%$ of anthropogenic $\mathrm{NH}_{3}$ emissions are outside of the European Union, China, and the U.S., which warrants further evaluations of this inventory.

\section{Appendix A: Description of the MASAGE_NH3 Model}

We present here a global process-based inventory of $\mathrm{NH}_{3}$ emissions called MASAGE_NH3 (Magnitude and Seasonality of Agricultural Emissions for $\mathrm{NH}_{3}$, https://fpaulot.bitbucket.org/MASAGE/). This inventory is constructed on a $0.5^{\circ} \times 0.5^{\circ}$ horizontal grid and focuses on providing improved sector-resolved estimates for agricultural emissions. We use MASAGE_NH3 in the text to interpret the seasonal and spatial patterns of $\mathrm{NH}_{3}$ emissions suggested by our inversion. Portions of the MASAGE model (e.g., crop model and livestock distribution) can be readily used to investigate other agricultural emissions (e.g., methane and $\mathrm{N}_{2} \mathrm{O}$ ).

\section{A1. Mineral Fertilizer Emissions}

$\mathrm{NH}_{3}$ emission from fertilizer application depends on the crop-dependent application rate (e.g., soybean requires much less $\mathrm{N}$ input than corn), the application technique (broadcast and injection result in very different emissions), and physical parameters (temperature and wind speed).

In each grid square, $\mathrm{NH}_{3}$ emissions from mineral fertilizer application $\left(E_{F}\right)$ at time $t$ are given by

$$
E_{F}(t)=\sum_{c} \alpha_{c} \Gamma_{c} A_{c} \psi_{c}(t)
$$

where $A_{c}$ is the area occupied by crop $c$ from the Monthly Irrigated and Rainfed Crop Areas (MIRCA) data set $\left(0.5^{\circ} \times 0.5^{\circ}\right.$, Portmann et al. [2010]), $\Gamma_{c}$ is the country-specific fertilizer application rate, $\alpha_{c}$ is the annual $\mathrm{NH}_{3}$ emission factor, and $\psi_{c}$ is the crop-specific application function (see $\mathrm{A} 2$ ). $\Gamma_{c}$ is calculated annually using annual fertilizer consumption [FAOSTAT, 2009], harvested area, and crop-specific fertilizer application rate over the 2006-2007 period (International Fertilizer industry Association (IFA), Heffer [2009]). $\alpha_{c}$ is calculated following Bouwman et al. [2002b] and includes the effect of fertilizer type (updated annually from country-specific consumption (IFA)), soil pH and cation exchange capacity (from International Soil Reference and Information Centre - World Soil Information), application techniques, and crop type. We neglect the effect of latitude, a proxy for temperature as it is represented through $C(t)$ (see $(\mathrm{A} 3)$ ). $A_{c}$ varies annually according to national statistics [FAOSTAT, 2009]. Based on the specificity of the MIRCA and IFA data sets, the following crops are treated independently: wheat, winter wheat, rice, rice (double cropping), corn, other cereals (barley and millet), other winter cereals (barley and millet), tropical cereals (sorghum and millet), soybean, oil palm, rapeseed, groundnuts, cotton, sugar cane, temperate roots (sugar beet), fruits and vegetables, tropical roots (cassava), pulses, and other perennial crops.

Plot experiments show that most $\mathrm{NH}_{3}$ emissions from fertilizer take place within a few days of application [Plöchl, 2001]. Following Skjøth et al. [2004] and Gyldenkærne et al. [2005], we assume that $\mathrm{NH}_{3}$ emission from 
fertilizer can be represented by a Gaussian:

$$
\psi_{c}(t)=N C(t) \sum_{a=1}^{3} \frac{\beta_{a, c}}{\sigma_{a, c} \sqrt{2 \pi}} e^{-\left(\frac{t-\tau_{a, c}}{\sigma_{a, c}}\right)^{2}}
$$

where $\beta_{a, c}$ is the crop-specific fraction of fertilizer applied at each stage $(a), \tau_{a, c}$ is the crop-specific optimal application date, $\sigma_{a, c}$ is the deviation around this date [Gyldenkærne et al., 2005], $N$ is a normalization factor defined below, and $C$ accounts for the effect of temperature $\left(T_{C}\right.$, the air temperature at $2 \mathrm{~m}$ in $\left.{ }^{\circ} \mathrm{C}\right)$ and wind

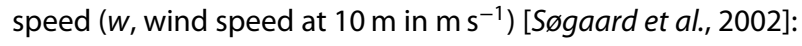

$$
C(t)=1.02^{T_{C}} \times 1.04^{w}
$$

Three application stages (a) are considered: (1) at planting, (2) at the peak of nutrient demand (referred to as "at growth" hereafter), and (3) after harvest. We assume $\sigma_{1, c}=9$ days and $\sigma_{2, c}=\sigma_{3, c}=16$ days [Gyldenkærne et al., 2005; Skjøth et al., 2004] for most crops (see exceptions below). Planting dates $\left(\tau_{1, c}\right)$ are determined using a temperature and/or precipitation threshold as used in the Lund-Potsdam-Jena managed Land model [Bondeau et al., 2007]. When planting dates are fixed (e.g., soybean) or not defined (e.g., cotton), we use a global survey of planting dates [Sacks et al., 2010], when possible, and Moderate Resolution Imaging Spectroradiometer (MODIS) green-up dates averaged from 2001 to 2004 otherwise [Ganguly et al., 2010; Hudman et al., 2012]. Growth application $\left(\tau_{2, c}\right)$ and harvest $\left(\tau_{3, c}\right)$ dates are determined using accumulated growing degree days (GDD) since planting [McMaster and Wilhelm, 1997]

$$
\mathrm{GDD}=\frac{\max \left(T_{\min }, T_{b}\right)+\max \left(\min \left(T_{H}, T_{\max }\right), T_{b}\right)}{2}-T_{b}
$$

where $T_{\max }$ and $T_{\min }$ are the maximum and minimum daily temperature, respectively, $T_{H}=303 \mathrm{~K}$ (except for tropical crops for which no upper limit is considered), and $T_{b}$ is the crop-specific base temperature, below which no growth is observed. Harvest can be triggered by crop maturity [Bondeau et al., 2007] or hard frost (defined as an average $24 \mathrm{~h}$ temperature lower than $-2^{\circ} \mathrm{C}$ ). Fertilizers are applied after harvest when soil temperature drops below $10^{\circ} \mathrm{C}$ [Goebes et al., 2003]. When no harvesting date can be calculated or when no threshold is reported [Bondeau et al., 2007], we use a global survey of harvesting dates [Sacks et al., 2010], when possible, and MODIS brown-down dates averaged from 2001 to 2004 otherwise. For fruits and vegetables, planting, harvesting, and growth application are defined as the start, end, and middle of the growing season as defined by MODIS green-up and brown-down dates. For the crops that rely on MODIS cropping dates (fruits and vegetables, oil palm, sugar cane, and other perennial crops), we use $\sigma_{1, c}=\sigma_{3, c}=30$ days and $\sigma_{2, c}=60$ days to reflect the uncertainty in cropping practices. $N$ is defined such that

$$
N=\frac{\int_{2005}^{2008} \sum_{\Omega} \sum_{c} \alpha_{c} \Gamma_{c} A_{c} \mathrm{~d} t}{\int_{2005}^{2008} \sum_{\Omega} \sum_{c} \alpha_{c} \Gamma_{c} A_{c} \psi_{c}(t) \mathrm{d} t}
$$

where $\Omega$ designates the ensemble of GEOS-Chem grid squares. This normalization allows for interannual variability in meteorology to affect $\mathrm{NH}_{3}$ emissions while imposing a multiyear total from the fertilizer application rate.

A large source of uncertainty lies in the fraction $\beta_{a, c}$ of fertilizer applied at each stage. In the U.S., Goebes et al. [2003] reported that fertilization of soybean in Illinois takes place mostly in the month preceding planting and in the fall. Pinder et al. [2004b] report significant manure application in the spring and fall. However, in parts of Europe (e.g., Denmark), most of the application of fertilizer and manure takes place in spring and during the growing season [Gyldenkærne et al., 2005; Skjøth et al., 2008]. In the absence of global data sets of fertilization practices, the following assumptions are made. For wheat, corn, temperate roots, and other cereals, we assume that $60 \%$ of fertilizer is applied at planting, $20 \%$ at growth, and $20 \%$ at harvest. For crops that require vernalization (winter wheat, winter cereals, and rapeseed), we assume that $10 \%$ of fertilizer is applied at planting, $70 \%$ at growth, and $20 \%$ at harvest. For fruits and vegetables, we assume $20 \%$ application at planting, $60 \%$ at growth, and $20 \%$ at harvest. For all other crops, we assume that $80 \%$ of fertilizer is applied at planting and $20 \%$ at harvest. A more realistic treatment would require accounting for crop nutrient demand [Cooter et al., 2012] and differences in regional practices. 


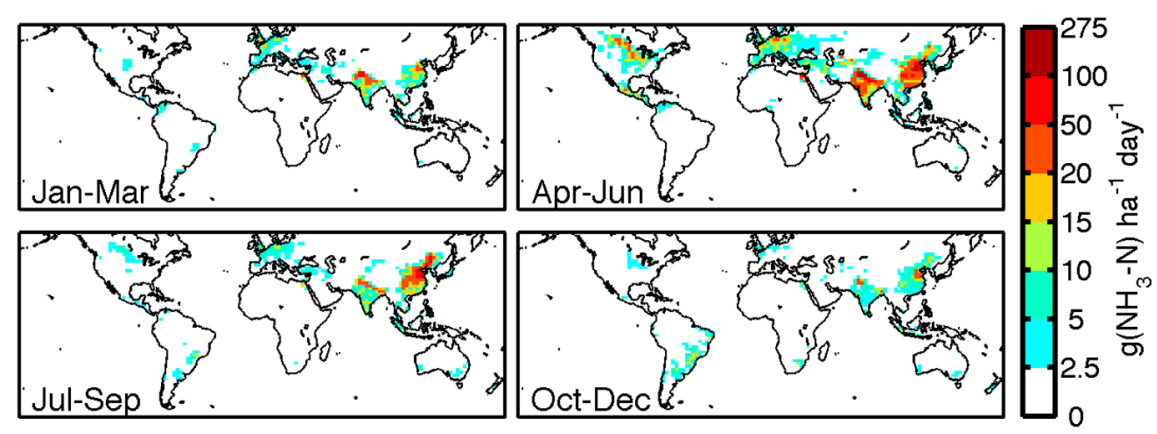

Figure A1. MASAGE_NH3 emissions of $\mathrm{NH}_{3}$ from fertilizer.

The crop model used by MASAGE_NH3 does not account for double cropping. This leads to erroneous planting dates [Portmann et al., 2010], especially in Asia, where this practice is common. For instance, in the winter wheat-summer corn rotation, corn is seeded in June [Huang et al., 2012], rather than in April as simulated by the crop model. To account for this delay, we assume that all corn in China is planted when wheat is harvested. Fertilizer application techniques is a critical uncertainty in our model. For instance, Bouwman et al. [2002a] found that $\mathrm{NH}_{3}$ emissions following fertilizer injection are $50 \%$ lower than following fertilizer broadcasting. The default assumption in MASAGE_NH3 is that fertilization is through broadcasting, except for anhydrous ammonia and nitrogen solution, which are injected. Early evaluation of MASAGE_NH3 with the adjoint optimization results led to some further adjustments: $\mathrm{NH}_{3}$ emissions from fertilizer application in China are reduced by $25 \%$ and $\mathrm{NH}_{3}$ emissions from fertilizer application to U.S. corn are reduced by $40 \%$.

Figure $\mathrm{A} 1$ shows the MASAGE_NH3 seasonal distribution of $\mathrm{NH}_{3}$ emissions from fertilizer application, and Table $\mathrm{A} 1$ shows the emissions associated with different crop categories. Emissions peak in spring throughout the Northern Hemisphere, reflecting the dominant fertilizer application at crop planting.

Table A1 shows the emissions associated with the different crop categories used by MASAGE_NH3. The largest emitting crops are corn in the U.S., and wheat (including winter wheat) in the European Union, China, and the rest of the world.

\section{A2. Manure Emissions}

$\mathrm{NH}_{3}$ emissions from manure depend on the nitrogen content of the feed and on manure management practices at the housing, storage, and land application stages. In each grid square, $\mathrm{NH}_{3}$ emissions from manure $\left(E_{M}\right)$ at time $t$ are given by the following:

$$
E_{M}(t)=\sum_{l} \alpha_{l} D_{l}\left[\gamma_{h, l} \Gamma_{h, l} \psi_{h, l}(t)+\gamma_{s, l} \Gamma_{s, l} \psi_{s, l}(t)+\gamma_{a, l} \Gamma_{a, l}\left(P \alpha_{p} C(t)+(1-P) \sum_{c} \alpha_{c} \psi_{c}(t)\right)\right]
$$

where $I$ is a livestock category (Table A1), $D_{l}$ is the animal density $\left(0.5^{\circ} \times 0.5^{\circ}\right), \alpha_{l}, \alpha_{c^{\prime}}$ and $\alpha_{p}$ are the livestock, crop, and pasture $\mathrm{NH}_{3}$ emission factors, $\gamma_{h, l}, \gamma_{s, l}$, and $\gamma_{a, l}$ are the fractions of emissions associated with housing, storage, and manure application, $P$ is the fraction of manure applied to pasture, $\psi_{h, l}$ and $\psi_{s, l}$ are the dependences of housing and storage emissions on temperature and wind speed [Gyldenkærne et al., 2005], and $\Gamma_{h, l}, \Gamma_{s, l}$ and $\Gamma_{a, l}$ are normalization factors defined below. $D_{l}$ is taken from the FAO-gridded livestock of the world [Wint and Robinson, 2007] and adjusted annually according to country-specific FAO statistics [FAOSTAT, 2009]. $P$ is taken as the fraction of pasture in each grid cell [Ramankutty et al., 2008]. The timing of manure application to cropland is assumed to be the same as that of mineral fertilizer application (see section A1). Manure is applied to pasture throughout the year. $\alpha_{l}$ are taken from Faulkner and Shaw [2008] for the U.S. and Canada, Velthof et al. [2012] for the Benelux, Denmark, and Germany, the GAINS model for other European countries and East Asia (including China), and Bouwman et al. [2002b] for the rest of the world. $\alpha_{l}$ represent "country-average" management practices and do not capture regional variations. This is an important limitation for large countries such as the U.S. or China. For each of these regions, $\Gamma_{h, l}$ is defined such that

$$
\Gamma_{h, l}=\frac{\int_{2005}^{2008} \sum_{\Omega_{R}} \alpha_{l} D_{l} \gamma_{h, l} \mathrm{~d} t}{\int_{2005}^{2008} \sum_{\Omega_{R}} \alpha_{l} D_{l} \gamma_{h, l} \psi_{h, l}(t) \mathrm{d} t}
$$

where $\Omega_{R}$ designates the ensemble of grid squares in region $R . \Gamma_{s, l}$ and $\Gamma_{a, l}$ are defined similar to $\Gamma_{h, l}$. 
Table A1. $\mathrm{NH}_{3}$ Emissions in GEOS-Chem Including MASAGE_NH3 for Agriculture ${ }^{\mathrm{a}}$

\begin{tabular}{|c|c|c|c|c|}
\hline & Contiguous U.S. & European Union & China & World \\
\hline Anthropogenic & 2425 & 2725 & 7920 & 35295 \\
\hline Agriculture ${ }^{b}$ & 2180 & 2595 & 7810 & 33970 \\
\hline \multicolumn{5}{|l|}{ Crops } \\
\hline Cotton & 20 & 0 & 180 & 700 \\
\hline Corn & 200 & 80 & 735 & 1790 \\
\hline Fruits and Vegetables & 15 & 25 & 505 & 815 \\
\hline Groundnuts & 0 & 0 & 50 & 85 \\
\hline Oil Palm & 0 & 0 & 0 & 125 \\
\hline Other Cereal' ${ }^{c}$ & 10 & 45 & 5 & 125 \\
\hline Other Cereal (Winter) ${ }^{c}$ & 15 & 90 & 30 & 335 \\
\hline Other Crops ${ }^{d}$ & 95 & 95 & 185 & 980 \\
\hline Pulses & 0 & 0 & 15 & 45 \\
\hline Rapeseed & 0 & 30 & 60 & 155 \\
\hline Early Rice & 5 & 0 & 145 & 555 \\
\hline Late Rice & 0 & 0 & 150 & 325 \\
\hline Soybeans & 5 & 0 & 45 & 85 \\
\hline Sugar Cane & 5 & 0 & 60 & 455 \\
\hline Temperate Roots & 5 & 25 & 305 & 480 \\
\hline Tropical Cereals & 0 & 0 & 0 & 90 \\
\hline Tropical Roots & 0 & 0 & 25 & 160 \\
\hline Wheat & 40 & 25 & 105 & 435 \\
\hline Winter Wheat & 55 & 195 & 425 & 1630 \\
\hline \multicolumn{5}{|l|}{ Manure } \\
\hline Beef & 755 & 495 & 850 & 10080 \\
\hline Buffalo & 0 & 30 & 195 & 1520 \\
\hline Dairy & 370 & 530 & 35 & 3280 \\
\hline Goat & 0 & 10 & 135 & 695 \\
\hline Poultry & 280 & 300 & 1335 & 3985 \\
\hline Pork & 295 & 525 & 2125 & 4075 \\
\hline Sheep & 5 & 85 & 115 & 960 \\
\hline Biofuel $^{\mathrm{e}}$ & 20 & 35 & 90 & 800 \\
\hline Other anthropogenic ${ }^{f}$ & 225 & 95 & 25 & 525 \\
\hline \multicolumn{5}{|l|}{ Natural } \\
\hline Open fires ${ }^{g}$ & 50 & 25 & 40 & 5540 \\
\hline Other natural ${ }^{\mathrm{h}}$ & 265 & 195 & 405 & 13655 \\
\hline Total & 2740 & 2945 & 8365 & 54490 \\
\hline
\end{tabular}

${ }^{\mathrm{a}} \mathrm{GgNH}_{3}-\mathrm{Na}^{-1}$. Values are for 2005-2008 except for biofuel and other anthropogenic sources (2000).

${ }^{b}$ From MASAGE_NH3 (this work).

'Barley and rye [Portmann et al., 2010].

${ }^{d}$ Include forestry, pasture, and ornamentals [Heffer, 2009].

e Residential (33\%) + agricultural waste $(67 \%)$ in 2000 from the Atmospheric Chemistry and Climate Model Intercomparison Project (ACCMIP) [Lamarque et al., 2010].

${ }^{f}$ Transportation (73\%), industry (23\%), and energy (4\%) in 2000 from ACCMIP [Lamarque et al., 2010].

gFrom GFED2 [Randerson et al., 2006].

${ }^{h}$ From GEIA [Bouwman et al., 1997], mostly from oceanic sources.

Dairy cattle produces significantly more $\mathrm{NH}_{3}$ than beef cattle because of greater protein intake. The FAO livestock inventory does not distinguish between dairy and beef cattle. To estimate the fraction of dairy cattle in each grid box, we use a previous global-gridded inventory of dairy and beef cattle [Lerner et al., 1988], which is superseded in the U.S. by the 2007 agricultural census (http://quickstats.nass.usda.gov/) and by the Statistical Office of the European Communities (EUROSTAT) in the European Union (http://epp.eurostat.ec.europa.eu). In the U.S., dairy emission factors ( $\left.\alpha_{\text {dairy }}\right)$ are taken from Pinder et al. [2004a, 2004b].

$\mathrm{NH}_{3}$ emission factors associated with beef can span a very large range depending on breeding practices. Faulkner and Shaw [2008] suggest $\alpha_{\text {beef }}=7.4 \mathrm{~kg} \mathrm{NH}_{3}-\mathrm{N}$ head ${ }^{-1} \mathrm{a}^{-1}$ for cow-calf systems and 


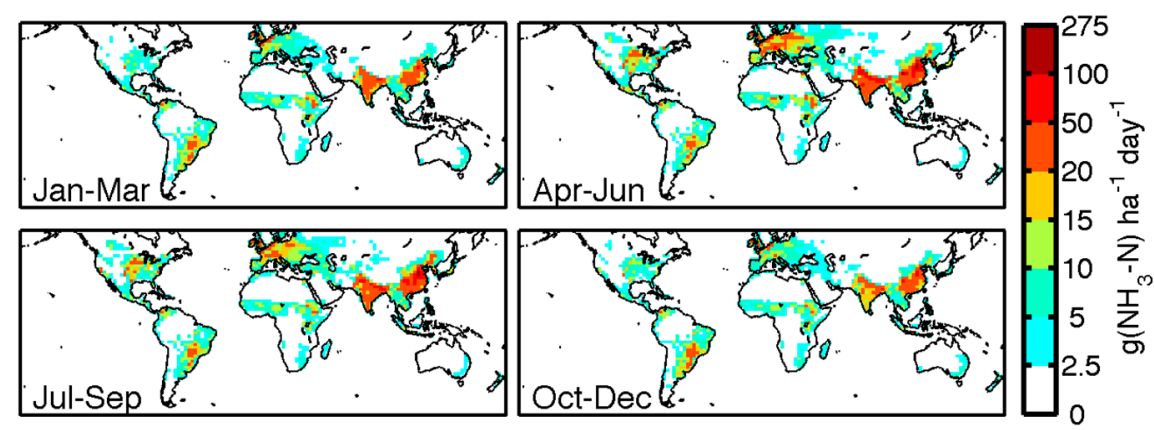

Figure A2. MASAGE_NH3 emissions of $\mathrm{NH}_{3}$ from manure.

$10.7 \mathrm{~kg} \mathrm{NH}_{3}-\mathrm{N}$ head ${ }^{-1} \mathrm{a}^{-1}$ for feedyards. However, much higher emission factors have been measured at concentrated animal feeding operations (CAFO), which may reflect different manure management practices [Todd et al., 2008; Hristov et al., 2011]. MASAGE_NH3 does not currently use information on management practices. To account for increased emissions from feed lots, such as CAFO, we assume that the emission factor of beef is linearly related to the animal density $(D)$, which is very high at CAFO.

$$
\alpha_{\text {beef }}\left(\mathrm{kg} \mathrm{NH}_{3}-\mathrm{N}_{\text {head }}{ }^{-1} \mathrm{a}^{-1}\right)=\left\{\begin{array}{cc}
7.4 & D_{\text {beef }}<15 \text { head km }^{-2} \\
0.25 D \text { (beef) }+3.65 & D_{\text {beef }} \geq 15 \text { head km }^{-2}
\end{array}\right.
$$

Figure $\mathrm{A} 2$ shows the global distribution of $\mathrm{NH}_{3}$ from manure in different season. Globally, beef is the largest source of $\mathrm{NH}_{3}$ from manure (and also the largest anthropogenic source) but dairy cattle and pork are the largest sources of $\mathrm{NH}_{3}$ in Europe and China, respectively (Table A1).

\section{Acknowledgments}

F.P. thanks Rynda Hudman Kay (EPA) for providing the MODIS green-up and brown-down data set and Giulia Conchedda (FAO) for assistance with the FAO-gridded livestock of the world product. F.P. thanks Paul O. Wennberg for the use of the HP cluster of the Caltech Division of Geology and Planetary Sciences. This work was supported by the NASA Applied Science Program as part of the Air Quality Applied Science Team (AQAST) F.P. was supported by a Harvard University Center for the Environment fellowship. D.K.H. recognizes support from NASA ACMAP NNX10AG63G and EPA-STAR RD83455901. We acknowledge the E-OBS dataset from the EU-FP6 project ENSEMBLES (http://ensembles-eu.metoffice.com) and the data providers in the ECA\&D project (http://www.ecad.eu) The ACCMIP inventory was downloaded from the ECCAD-Ether portal. Although this work was reviewed by EPA and approved for publication, it may not necessarily reflect official agency policy.

\section{References}

Adams, P. J., J. H. Seinfeld, D. Koch, L. Mickley, and D. Jacob (2001), General circulation model assessment of direct radiative forcing by the sulfate-nitrate-ammonium-water inorganic aerosol system, J. Geophys. Res., 106(D1), 1097-1111, doi:10.1029/2000JD900512.

Amos, H. M., et al. (2012), Gas-particle partitioning of atmospheric Hg(II) and its effect on global mercury deposition, Atmos. Chem. Phys., 12(1), 591-603.

Aneja, V. P., J. P. Chauhan, and J. T. Walker (2000), Characterization of atmospheric ammonia emissions from swine waste storage and treatment lagoons, J. Geophys. Res., 105(D9), 11,535-11,545.

Aneja, V. P., W. H. Schlesinger, and J. W. Erisman (2009), Effects of agriculture upon the air quality and climate: Research, policy, and regulations, Environ. Sci. Technol., 43(12), 4234-4240.

Arellano, A. F., and P. G. Hess (2006), Sensitivity of top-down estimates of CO sources to GCTM transport, Geophys. Res. Lett., 33, L21807, doi:10.1029/2006GL027371.

Barrett, S., et al. (2012), Public health, climate, and economic impacts of desulfurizing jet fuel, Environ. Sci. Technol., 46(8), 4275-4282.

Bash, J. O., E. J. Cooter, R. L. Dennis, J. T. Walker, and J. E. Pleim (2013), Evaluation of a regional air-quality model with bidirectional $\mathrm{NH}_{3}$ exchange coupled to an agroecosystem model, Biogeosciences, 10(3), 1635-1645, doi:10.5194/bg-10-1635-2013.

Battye, W., and R. Barrows (2004), Review of ammonia emission modeling techniques for natural landscapes and fertilized soils, Tech. Rep., US EPA.

Beusen, A., A. Bouwman, P. Heuberger, G. V. Drecht, and K. V. D. Hoek (2008), Bottom-up uncertainty estimates of global ammonia emissions from global agricultural production systems, Atmos. Environ., 42(24), 6067-6077.

Binkowski, F. S., and S. J. Roselle (2003), Models-3 Community Multiscale Air Quality (CMAQ) model aerosol component 1. Model description, J. Geophys. Res., 108(D6), 4183, doi:10.1029/2001JD001409.

Bobbink, R., et al. (2010), Global assessment of nitrogen deposition effects on terrestrial plant diversity: A synthesis, Ecol. Appl., 20(1), 30-59.

Bondeau, A., et al. (2007), Modelling the role of agriculture for the 20th century global terrestrial carbon balance, Global Change Biol., 13(3), 679-706.

Bouwman, A., D. Van Vuuren, R. Derwent, and M. Posch (2002a), A global analysis of acidification and eutrophication of terrestrial ecosystems, Water Air Soil Pollut., 141, 349-382, doi:10.1023/A:1021398008726.

Bouwman, A. F., D. S. Lee, W. A. H. Asman, F. J. Dentener, K. W. Van Der Hoek, and J. G. J. Olivier (1997), A global high-resolution emission inventory for ammonia, Global Biogeochem. Cycles, 11(4), 561-587.

Bouwman, A. F., L. J. M. Boumans, and N. H. Batjes (2002b), Estimation of global $\mathrm{NH}_{3}$ volatilization loss from synthetic fertilizers and animal manure applied to arable lands and grasslands, Global Biogeochem. Cycles, 16(2), 1024, doi:10.1029/2000GB001389.

Brink, C., and H. van Grinsven (2011), The European Nitrogen Assessment: Sources, Effects and Policy Perspectives, chap. 22, Cambridge Univ. Press, Cambridge.

Byrd, R. H., P. Lu, J. Nocedal, and C. Zhu (1994), A limited-memory algorithm for bound constrained optimization, SIAM J. Sci. Comput., 16(5), 1190-1208

Conforti, P. (Eds. ) (2011), Looking Ahead in World Food and Agriculture: Perspectives to 2050, Food and Agriculture Organization of the United Nations, Rome.

Cooter, E. J., J. O. Bash, V. Benson, and L. Ran (2012), Linking agricultural crop management and air quality models for regional to national-scale nitrogen assessments, Biogeosciences, 9(10), 4023-4035. 
Di Luzio, M., G. L. Johnson, C. Daly, J. K. Eischeid, and J. G. Arnold (2008), Constructing retrospective gridded daily precipitation and temperature datasets for the conterminous United States, J. Appl. Meteorol., 47(2), 475-497.

Dise, N. B. (2011), The European Nitrogen Assessment: Sources, Effects and Policy Perspectives, chap. 20, Cambridge Univ. Press, Cambridge.

Drummond, M. A., and T. R. Loveland (2010), Land-use pressure and a transition to forest-cover loss in the eastern United States, Bioscience, 60(4), 286-298, doi:10.1525/bio.2010.60.4.7.

Erisman, J. W., M. A. Sutton, J. Galloway, Z. Klimont, and W. Winiwarter (2008), How a century of ammonia synthesis changed the world, Nat. Geosci., 1(10), 636-639.

European Commission, JRC/PBL (2011), Emission database for global atmospheric research (EDGAR), release version 4.2.

FAOSTAT (2009), Agriculture Organization of the United Nations. Statistical Database.

Faulkner, W., and B. Shaw (2008), Review of ammonia emission factors for United States animal agriculture, Atmos. Environ., 42(27), 6567-6574.

Fisher, J. A., et al. (2011), Sources, distribution, and acidity of sulfate-ammonium aerosol in the Arctic in winter-spring, Atmos. Environ., $45,7301-7318$.

Friedrich, R., and S. Reis (2004), Emissions of Air Pollutants: Measurements, Calculations and Uncertainties, Springer, Berlin Heidelberg, New York.

Galloway, J. N., et al. (2004), Nitrogen cycles: Past, present, and future, Biogeochemistry, 70(2), 153-226.

Ganguly, S., M. A. Friedl, B. Tan, X. Zhang, and M. Verma (2010), Land surface phenology from MODIS: Characterization of the collection 5 global land cover dynamics product, Remote Sens. Environ., 114(8), 1805-1816.

Gilliland, A. B., R. L. Dennis, S. J. Roselle, and T. E. Pierce (2003), Seasonal $\mathrm{NH}_{3}$ emission estimates for the eastern United States based on ammonium wet concentrations and an inverse modeling method, J. Geophys. Res., 108(D15), 4477, doi:10.1029/2002JD003063.

Gilliland, A. B., K. W. Appel, R. W. Pinder, and R. L. Dennis (2006), Seasonal $\mathrm{NH}_{3}$ emissions for the continental United States: Inverse model estimation and evaluation, Atmos. Environ., 40(26), 4986-4998.

Goebes, M. D., R. Strader, and C. Davidson (2003), An ammonia emission inventory for fertilizer application in the United States, Atmos. Environ., 37, 2539-2550.

Grizzetti, B. (2011), The European Nitrogen Assessment: Sources, Effects and Policy Perspectives, chap. 17, Cambridge Univ. Press, Cambridge.

Gyldenkærne, S., C. A. Skjøth, O. Hertel, and T. Ellermann (2005), A dynamical ammonia emission parameterization for use in air pollution models, J. Geophys. Res., 110, D07108, doi:10.1029/2004JD005459.

Haylock, M. R., N. Hofstra, A. M. G. Klein Tank, E. J. Klok, P. D. Jones, and M. New (2008), A European daily high-resolution gridded data set of surface temperature and precipitation for 1950-2006, J. Geophys. Res., 113, D20119, doi:10.1029/2008JD010201.

Heald, C., D. Jacob, D. Jones, P. Palmer, J. Logan, D. Streets, G. Sachse, J. Gille, R. Hoffman, and T. Nehrkorn (2004), Comparative inverse analysis of satellite (MOPITT) and aircraft (TRACE-P) observations to estimate Asian sources of carbon monoxide, J. Geophys. Res., 109, D23306, doi:10.1029/2004JD005185.

Heald, C. L., et al. (2012), Atmospheric ammonia and particulate inorganic nitrogen over the United States, Atmos. Chem. Phys., 12(21), $10,295-10,312$.

Heffer, P. (2009), Assessment of Fertilizer Use by Crop at the Global Level 2006/07-2007/08, IFA, Paris, France.

Henze, D. K., A. Hakami, and J. H. Seinfeld (2007), Development of the adjoint of GEOS-Chem, Atmos. Chem. Phys., 7(9), 2413-2433.

Henze, D. K., J. H. Seinfeld, and D. T. Shindell (2009), Inverse modeling and mapping US air quality influences of inorganic $\mathrm{PM}_{2.5}$ precursor emissions using the adjoint of GEOS-Chem, Atmos. Chem. Phys., 9(16), 5877-5903.

Hjellbrekke, A. G., and A. M. Fjaeraa (2008), Data report 2008 acidifying and eutrophying compounds and particulate matter, Tech. Rep., EMEP.

Holland, E. A., F. J. Dentener, B. H. Braswell, and J. M. Sulzman (1999), Contemporary and pre-industrial global reactive nitrogen budgets, Biogeochemistry, 46, 7-43, doi:10.1007/BF01007572.

Houlton, B. Z., E. Boyer, A. Finzi, J. Galloway, A. Leach, D. Liptzin, J. Melillo, T. S. Rosenstock, D. Sobota, and A. R. Townsend (2012), Intentional versus unintentional nitrogen use in the United States: Trends, efficiency and implications, Biogeochemistry, 114, 1-13.

Hristov, A. N., M. Hanigan, A. Cole, R. Todd, T. A. McAllister, P. M. Ndegwa, and A. Rotz (2011), Review: Ammonia emissions from dairy farms and beef feedlots, Can. J. Anim. Sci., 91(1), 1-35.

Huang, X., Y. Song, M. Li, J. Li, Q. Huo, X. Cai, T. Zhu, M. Hu, and H. Zhang (2012), A high-resolution ammonia emission inventory in China, Global Biogeochem. Cycles, 26, GB1030, doi:10.1029/2011GB004161.

Hudman, R. C., N. E. Moore, A. K. Mebust, R. V. Martin, A. R. Russell, L. C. Valin, and R. C. Cohen (2012), Steps towards a mechanistic model of global soil nitric oxide emissions: Implementation and space based-constraints, Atmos. Chem. Phys., 12(16), 7779-7795.

Hutchings, N., S. Sommer, J. Andersen, and W. Asman (2001), A detailed ammonia emission inventory for Denmark, Atmos. Environ., 35(11), 1959-1968, doi:10.1016/S1352-2310(00)00542-2.

Indicator Reporting on the Integration of Environmental Concerns into Agriculture Policy (2005), Atmospheric emissions of ammonia from agriculture, Tech. Rep., EUROSTAT.

Klimont, Z., and C. Brink (2004), Modelling of emissions of air pollutants and greenhouse gases from agricultural sources in Europe, Tech. Rep., IIASA.

Lamarque, J.-F., et al. (2010), Historical (1850-2000) gridded anthropogenic and biomass burning emissions of reactive gases and aerosols: Methodology and application, Atmos. Chem. Phys., 10(15), 7017-7039.

Latysh, N., and G. Wetherbee (2012), Improved mapping of national atmospheric deposition program wet-deposition in complex terrain using PRISM-gridded data sets, Environ. Monit. Assess., 184, 913-928, doi:10.1007/s10661-011-2009-7.

Lerner, J., E. Matthews, and I. Fung (1988), Methane emission from animals: A global high-resolution data base, Global Biogeochem. Cycles, 2(2), 139-156.

Li, C., W. Salas, R. Zhang, C. Krauter, A. Rotz, and F. Mitloehner (2012), Manure-DNDC: A biogeochemical process model for quantifying greenhouse gas and ammonia emissions from livestock manure systems, Nutr. Cycling Agroecosyst., 93(2), 163-200, doi:10.1007/s10705-012-9507-z.

Liu, H., D. J. Jacob, I. Bey, and R. M. Yantosca (2001), Constraints from ${ }^{210} \mathrm{~Pb}$ and ${ }^{7} \mathrm{Be}$ on wet deposition and transport in a global three-dimensional chemical tracer model driven by assimilated meteorological fields, J. Geophys. Res., 106, 12,109-12,128.

Liu, X., et al. (2013), Enhanced nitrogen deposition over China, Nature, 494(7438), 459-462.

Martin, S. T., H.-M. Hung, R. J. Park, D. J. Jacob, R. J. D. Spurr, K. V. Chance, and M. Chin (2004), Effects of the physical state of tropospheric ammonium-sulfate-nitrate particles on global aerosol direct radiative forcing, Atmos. Chem. Phys., 4(1), 183-214, doi:10.5194/acp-4-183-2004.

Massad, R.-S., E. Nemitz, and M. A. Sutton (2010), Review and parameterisation of bi-directional ammonia exchange between vegetation and the atmosphere, Atmos. Chem. Phys., 10(21), 10,359-10,386, doi:10.5194/acp-10-10359-2010. 
McMaster, G. S., and W. Wilhelm (1997), Growing degree-days: One equation, two interpretations, Agric. For. Meteorol., 87(4), 291-300.

Mosier, A., J. Syers, and J. Freney (2004), Agriculture and the Nitrogen Cycle: Assessing the Impacts of Fertilizer Use on Food Production and the Environment, vol. 65, Island Pr., Washington, D. C.

Nowak, J. B., J. A. Neuman, R. Bahreini, A. M. Middlebrook, J. S. Holloway, S. A. McKeen, D. D. Parrish, T. B. Ryerson, and M. Trainer (2012), Ammonia sources in the California South Coast Air Basin and their impact on ammonium nitrate formation, Geophys. Res. Lett., 39, L07804, doi:10.1029/2012GL051197.

Olson, J. (1992), World ecosystems (WE1.4): Digital raster data on a 10 minute geographic 1080 x 2160 grid, Tech. Rep., NOAA Natl. Geophys, Data Center, Boulder, Colo.

Park, R. J., D. J. Jacob, B. D. Field, R. M. Yantosca, and M. Chin (2004), Natural and transboundary pollution influences on sulfate-nitrate-ammonium aerosols in the United States: Implications for policy, J. Geophys. Res., 109, D15204, doi:10.1029/2003JD004473.

Paulot, F., D. J. Jacob, and D. K. Henze (2013), Sources and processes contributing to nitrogen deposition: An adjoint model analysis applied to biodiversity hotspots worldwide, Environ. Sci. Technol., 47(7), 3226-3233.

Personne, E., B. Loubet, B. Herrmann, M. Mattsson, J. K. Schjoerring, E. Nemitz, M. A. Sutton, and P. Cellier (2009), SURFATM-NH3: A model combining the surface energy balance and bi-directional exchanges of ammonia applied at the field scale, Biogeosciences, 6(8), 1371-1388.

Pinder, R. W., E. A. Davidson, C. L. Goodale, T. L. Greaver, J. D. Herrick, and L. Liu (2012), Climate change impacts of US reactive nitrogen, Proc. Nat. Acad. Sci., 109(20), 7671-7675.

Pinder, R. W., N. J. Pekney, C. I. Davidson, and P. J. Adams (2004a), A process-based model of ammonia emissions from dairy cows: Improved temporal and spatial resolution, Atmos. Environ., 38(9), 1357-1365.

Pinder, R. W., R. Strader, C. I. Davidson, and P. J. Adams (2004b), A temporally and spatially resolved ammonia emission inventory for dairy cows in the United States, Atmos. Environ., 38(23), 3747-3756.

Pinder, R. W., P. J. Adams, S. N. Pandis, and A. B. Gilliland (2006), Temporally resolved ammonia emission inventories: Current estimates, evaluation tools, and measurement needs, J. Geophys. Res., 111, D16310, doi:10.1029/2005JD006603.

Pinder, R. W., J. T. Walker, J. O. Bash, K. E. Cady-Pereira, D. K. Henze, M. Luo, G. B. Osterman, and M. W. Shephard (2011), Quantifying spatial and seasonal variability in atmospheric ammonia with in situ and space-based observations, Geophys. Res. Lett., 38, L04802, doi:10.1029/2010GL046146.

Plöchl, M. (2001), Neural network approach for modelling ammonia emission after manure application on the field, Atmos. Environ., 35(33), 5833-5841.

Pope III, C., R. Burnett, M. Thun, E. Calle, D. Krewski, K. Ito, and G. Thurston (2002), Lung cancer, cardiopulmonary mortality, and long-term exposure to fine particulate air pollution, J. Am. Med. Assoc., 287(9), 1132-1141.

Pope III, C., M. Ezzati, and D. W. Dockery (2009), Fine-particulate air pollution and life expectancy in the United States, N. Engl. J. Med., 360(4), 376-386.

Portmann, F. T., S. Siebert, and P. Döll (2010), MIRCA2000-Global monthly irrigated and rainfed crop areas around the year 2000: A new high-resolution data set for agricultural and hydrological modeling, Global Biogeochem. Cycles, 24, GB1011, doi:10.1029/2008GB003435.

Puchalski, M. A., M. E. Sather, J. T. Walker, C. M. B. Lehmann, D. A. Gay, J. Mathew, and W. P. Robarge (2011), Passive ammonia monitoring in the United States: Comparing three different sampling devices, J. Environ. Monit., 13(11), 3156-3167, doi:10.1039/C1EM10553A.

Pye, H. O. T., H. Liao, S. Wu, L. J. Mickley, D. J. Jacob, D. K. Henze, and J. H. Seinfeld (2009), Effect of changes in climate and emissions on future sulfate-nitrate-ammonium aerosol levels in the United States, J. Geophys. Res., 114, D01205, doi:10.1029/2008JD010701.

Ramankutty, N., A. T. Evan, C. Monfreda, and J. A. Foley (2008), Farming the planet: 1. Geographic distribution of global agricultural lands in the year 2000, Global Biogeochem. Cycles, 22, GB1003, doi:10.1029/2007GB002952.

Randerson, J. T., G. R. van der Werf, L. Giglio, G. J. Collatz, and P. S. Kasibhatla (2006), Global Fire Emissions Database, Version 2 (GFEDv2), Tech. Rep., Oak Ridge Natl. Lab. Distributed Active Archive Center, Oak Ridge, Tenn.

Rebolledo, B., A. Gil, and J. Pallarés (2013), A spatial ammonia emission inventory for pig farming, Atmos. Environ., 64, 125-131.

Sacks, W., D. Deryng, J. Foley, and N. Ramankutty (2010), Crop planting dates: An analysis of global patterns, Global Ecol. Biogeogr., 19(5), 607-620.

Sala, O. E., et al. (2000), Global biodiversity scenarios for the year 2100, Science, 287(5459), 1770-1774.

Sander, S., et al. (2011), Chemical Kinetics and Photochemical Data for Use in Atmospheric Studies Evaluation Number 17, National Aeronautics and Space Administration, Jet Propulsion Laboratory, California Institute of Technology, Pasadena.

Schlesinger, W. H., and A. E. Hartley (1992), A global budget for atmospheric NH3, Biogeochemistry, 15(3), 191-211.

Shephard, M. W., et al. (2011), Tes ammonia retrieval strategy and global observations of the spatial and seasonal variability of ammonia, Atmos. Chem. Phys., 11(20), 10,743-10,763.

Simpson, D., et al. (1999), Inventorying emissions from nature in Europe, J. Geophys. Res., 104(D7), 8113-8152.

Skjøth, C. A., O. Hertel, S. Gyldenkærne, and T. Ellermann (2004), Implementing a dynamical ammonia emission parameterization in the large-scale air pollution model ACDEP, J. Geophys. Res., 109, D06306, doi:10.1029/2003JD003895.

Skjøth, C. A., T. Ellermann, O. Hertel, S. Gyldenkærne, and M. H. Mikkelsen (2008), Footprints on ammonia concentrations from environmental regulations, J. Air Waste Manage., 58(9), 1158-1165.

Skjøth, C. A., et al. (2011), Spatial and temporal variations in ammonia emission-A freely accessible model code for Europe, Atmos. Chem. Phys., 11(11), 5221-5236.

Søgaard, H., S. Sommer, N. Hutchings, J. Huijsmans, D. Bussink, and F. Nicholson (2002), Ammonia volatilization from field-applied animal slurry-The ALFAM model, Atmos. Environ., 36(20), 3309-3319.

Stevens, C. J., N. B. Dise, J. O. Mountford, and D. J. Gowing (2004), Impact of nitrogen deposition on the species richness of grasslands, Science, 303, 1876-1879.

Streets, D. G., et al. (2003), An inventory of gaseous and primary aerosol emissions in Asia in the year 2000, J. Geophys. Res., 108(D21), 8809, doi:10.1029/2002JD003093.

Tarantola, A. (2005), Inverse Problem Theory and Methods for Model Parameter Estimation, Society for Industrial Mathematics, Philadelphia.

Todd, R. W., N. A. Cole, R. N. Clark, T. K. Flesch, L. A. Harper, and B. H. Baek (2008), Ammonia emissions from a beef cattle feedyard on the southern High Plains, Atmos. Environ., 42(28), 6797-6805.

Tørseth, K., W. Aas, K. Breivik, A. M. Fjæraa, M. Fiebig, A. G. Hjellbrekke, C. Lund Myhre, S. Solberg, and K. E. Yttri (2012), Introduction to the European Monitoring and Evaluation Programme (EMEP) and observed atmospheric composition change during 1972-2009, Atmos. Chem. Phys., 12(12), 5447-5481.

U.S. EPA (2006), National emission inventory-Ammonia emissions from animal agricultural operations. 
Velthof, G., C. van Bruggen, C. Groenestein, B. de Haan, M. Hoogeveen, and J. Huijsmans (2012), A model for inventory of ammonia emissions from agriculture in the Netherlands, Atmos. Environ., 46, 248-255.

Walker, J. M., S. Philip, R. V. Martin, and J. H. Seinfeld (2012), Simulation of nitrate, sulfate, and ammonium aerosols over the United States, Atmos. Chem. Phys., 12(22), 11,213-11,227, doi:10.5194/acp-12-11213-2012.

Wang, Q., et al. (2011), Sources of carbonaceous aerosols and deposited black carbon in the Arctic in winter-spring: Implications for radiative forcing, Atmos. Chem. Phys., 11(23), 12,453-12,473.

Wang, Y., D. J. Jacob, and J. A. Logan (1998), Global simulation of tropospheric $\mathrm{O}_{3}-\mathrm{NO}_{x}$-hydrocarbon chemistry 1 . Model formulation, J. Geophys. Res., 103, 10,713-10,726.

Wesely, M. L. (1989), Parameterization of surface resistances to gaseous dry deposition in regional-scale numerical models, Atmos. Environ., 23(6), 1293-1304.

Wetherbee, G. A., N. E. Latysh, and J. D. Gordon (2005), Spatial and temporal variability of the overall error of National Atmospheric Deposition Program measurements determined by the USGS collocated-sampler program, water years 1989-2001, Environ. Pollut., 135(3), 407-418.

Wichink Kruit, R. J., M. Schaap, F. J. Sauter, M. C. van Zanten, and W. A. J. van Pul (2012), Modeling the distribution of ammonia across Europe including bi-directional surface-atmosphere exchange, Biogeosciences, 9(12), 5261-5277, doi:10.5194/bg-9-5261-2012.

Wint, W., and T. Robinson (2007), Gridded livestock of the world, Tech. Rep., Food and Agriculture Organization.

Yatagai, A., K. Kamiguchi, O. Arakawa, A. Hamada, N. Yasutomi, and A. Kitoh (2012), APHRODITE: Constructing a long-term daily gridded precipitation dataset for Asia based on a dense network of rain gauges, Bull. Am. Meteorol. Soc., 93, 1401-1415.

Zhang, L., D. J. Jacob, E. M. Knipping, N. Kumar, J. W. Munger, C. C. Carouge, A. van Donkelaar, Y. X. Wang, and D. Chen (2012), Nitrogen deposition to the United States: Distribution, sources, and processes, Atmos. Chem. Phys., 12(10), 4539-4554.

Zhang, Q., et al. (2007), Ubiquity and dominance of oxygenated species in organic aerosols in anthropogenically-influenced Northern Hemisphere midlatitudes, Geophys. Res. Lett., 34, L13801, doi:10.1029/2007GL029979.

Zhu, C., R. Byrd, P. Lu, and J. Nocedal (1997), Algorithm 778: L-BFGS-B: Fortran subroutines for large-scale bound-constrained optimization, ACM Trans. Math. Software (TOMS), 23(4), 550-560.

Zhu, L., D. K. Henze, K. E. Cady-Pereira, M. W. Shephard, M. Luo, R. W. Pinder, J. O. Bash, and G.-R. Jeong (2013), Constraining U.S. ammonia emissions using TES remote sensing observations and the GEOS-Chem adjoint model, J. Geophys. Res. Atmos., 118, 3355-3368, doi:10.1002/jgrd.50166. 